\title{
Thermodynamic and Radiative Structure of Stratocumulus-Topped Boundary Layers*
}

\author{
VIRENDRA P. GHATE \\ Environmental Science Division, Argonne National Laboratory, Argonne, Illinois \\ MARK A. MiLler \\ Department of Environmental Sciences, Rutgers, The State University of New Jersey, New Brunswick, New Jersey \\ Bruce A. Albrecht \\ Department of Atmospheric Sciences, University of Miami, Miami, Florida \\ CHRISTOPHER W. FAIRALL \\ NOAA/Earth System Research Laboratory, Boulder, Colorado
}

(Manuscript received 7 October 2013, in final form 4 September 2014)

\begin{abstract}
Stratocumulus-topped boundary layers (STBLs) observed in three different regions are described in the context of their thermodynamic and radiative properties. The primary dataset consists of 131 soundings from the southeastern Pacific (SEP), 90 soundings from the island of Graciosa (GRW) in the North Atlantic, and 83 soundings from the U.S. Southern Great Plains (SGP). A new technique that makes an attempt to preserve the depths of the sublayers within an STBL is proposed for averaging the profiles of thermodynamic and radiative variables. A one-dimensional radiative transfer model known as the Rapid Radiative Transfer Model was used to compute the radiative fluxes within the STBL. The SEP STBLs were characterized by a stronger and deeper inversion, together with thicker clouds, lower free-tropospheric moisture, and higher radiative flux divergence across the cloud layer, as compared to the GRW STBLs. Compared to the STBLs over the marine locations, the STBLs over SGP had higher wind shear and a negligible $\left(-0.41 \mathrm{~g} \mathrm{~kg}^{-1}\right)$ jump in mixing ratio across the inversion. Despite the differences in many of the STBL thermodynamic parameters, the differences in liquid water path at the three locations were statistically insignificant. The soundings were further classified as well mixed or decoupled based on the difference between the surface and cloud-base virtual potential temperature. The decoupled STBLs were deeper than the well-mixed STBLs at all three locations. Statistically insignificant differences in surface latent heat flux (LHF) between well-mixed and decoupled STBLs suggest that parameters other than LHF are responsible for producing decoupling.
\end{abstract}

\section{Introduction}

There is general agreement that varying depictions of the cloud feedbacks associated with boundary layer stratocumulus clouds in global climate models (GCMs) are partly responsible for the spread in predictions of the

\footnotetext{
* Supplemental information related to this paper is available at the Journals Online website: http://dx.doi.org/10.1175/JAS-D-130313.s1.

Corresponding author address: Virendra P. Ghate, 9700 S. Cass Ave., Argonne, IL 60439.

E-mail:vghate@anl.gov
}

magnitude of global warming (e.g., Bony and Dufresne 2005). Boundary layer stratocumulus clouds have higher albedo than the underlying sea or land surface; hence, comparatively, they reflect a higher percentage of incoming solar radiation back to space. Because they lie beneath a strong thermal inversion and have rather uniform cloud-top temperatures that are only $10^{\circ}-20^{\circ} \mathrm{C}$ cooler than the underlying surface, they emit a similar amount of longwave radiation to space as emitted from the surface in clear-sky conditions. Hence, the net radiative impact of stratocumulus clouds is to cool Earth's surface, and, as a consequence of their large areal coverage, their radiative feedbacks must be accurately portrayed in GCMs. Stratocumulus cloud systems exhibit 
horizontal variability at scales far smaller than a GCM grid cell and they often occur in sheets that are thinner than the vertical resolution of the model. As such, they must be parameterized using other resolved quantities supplied by the model.

Stratocumuli are intimately linked to the turbulence within the boundary layer. This turbulence is driven by radiative cooling near cloud top, surface buoyancy, drizzle evaporative cooling, wind shear, and evaporative cooling associated with entrainment. Specific combinations of these turbulent processes result in different configurations of cloud structure that produce different radiative throughputs. Changes in the profiles of the thermodynamic and radiative properties associated with turbulent transports may subdivide, or decouple, the stratocumulus cloud layer from the surface, perhaps leading to a cumulus-topped boundary layer or complete dissipation of the stratocumulus cloud (Bretherton and Wyant 1997; Lock 2009).

Stratocumulus cloud systems have been the focus of several field campaigns, including the First International Satellite Cloud Climatology Project (ISCCP) Regional Experiment (FIRE), the Atlantic Stratocumulus Experiment (ASTEX), the Dynamics and Chemistry of Marine Stratocumulus (DYCOMS-II), the Variability of American Monsoon System (VAMOS) OceanCloud-Atmosphere-Land Study (VOCALS) (Albrecht et al. 1988, 1995; Stevens et al. 2003; Wood et al. 2011), and many modeling studies. Parameterizations of ranging complexity have been used to represent stratocumulus clouds in GCMs. Some parameterizations use a simple measure of lower-tropospheric stability (Klein and Hartmann 1993; Wood and Bretherton 2006) to predict low-cloud amount (e.g., Miller 1997; Rasch and Kristjánsson 1998). Others predict turbulence in the boundary layer and couple it with the low-cloud amount (Lock et al. 2000; Bretherton and Park 2009) or use the higher-order moments of the probability distribution function (PDF) and joint PDF of vertical velocity and thermodynamic variables to predict the low-cloud amount (Larson et al. 2012; Golaz et al. 2002; Lappen and Randall 2001; etc.).

Under the auspices of the Global Energy and Water Cycle Experiment (GEWEX) Cloud System Study (GCSS) Working Group I, many studies focused on stratocumulus clouds have been performed (e.g., Moeng et al. 1996; Bechtold et al. 1996; Zhu et al. 2005; Wyant et al. 2007). Studies by Zhu et al. (2005) and Wyant et al. (2007) used data collected during the DYCOMS-II field campaign, while studies by Moeng et al. (1996) and Bechtold et al. (1996) used data from the FIRE field campaign. Additional parameterization comparison studies (Medeiros et al. 2012; Bretherton and Wyant
1997; Stevens et al. 1998; etc.) have focused on the transition of the stratocumulus-topped boundary layers (STBLs) from one mode to another. Almost all of these comparison studies report that their results are limited by the lack of a comprehensive observational climatology of the STBL.

In this study, we have used data from three different locations to develop a climatology of the thermodynamic and radiative structure of the STBL. An averaging technique that is designed to preserve the internal STBL structure is proposed for the thermodynamic and radiative properties. The data are then used to gain insights on the decoupling of the STBL by classifying them based on the difference between surface and cloud-base potential temperature. The data are described in the next section, which is followed by sections describing the methodology and the mean conditions. Mean thermodynamic and radiative structures of the well-mixed versus decoupled classification of STBL are reported in section 5. The article concludes with a summary and discussion section.

\section{Data}

Data from three locations have been used in this study. The first of these three locations is the northern coast of the small island of Graciosa (GRW), Azores, in the eastern North Atlantic; we use data collected during a deployment of the first Atmospheric Radiation Measurement Program (ARM) Mobile Facility (AMF-1) on the island. The second of these three locations is the permanent ARM observing facility near Lamont, Oklahoma, which is commonly referred to as the Southern Great Plains (SGP) facility. The final location is the Ocean Reference Station (ORS) in the southeastern Pacific (SEP), where yearly cruises are conducted by the National Oceanic and Atmospheric Administration (NOAA) Earth System Research Laboratory (ESRL)'s Physical Sciences Division (PSD), primarily during the Northern Hemisphere fall period. Instrumentation at the ARM sites is described in detail by Mather and Voyles (2013) and that on board the NOAA cruises by de Szoeke et al. (2012). Described below is the subset of the instrumentation used in this study. The radiative transfer model used to simulate the radiative fluxes is described in appendix A.

\section{a. Instrumentation}

\section{1) ARM SOUTHERn GReAT Plains}

Radiosondes are launched at the ARM SGP site four times a day at 0000, 0600, 1200, and 1800 UTC, which characterize the thermodynamic and wind structure of the atmosphere. A Ka-band (8-mm wavelength) vertically 
pointing millimeter cloud radar (MMCR) recorded the first three moments of the Doppler spectrum at a high temporal and spatial resolution at the SGP site. Data from the MMCR were then used to calculate the cloud boundaries and filtered reflectivity at $10-\mathrm{s}$ and $45-\mathrm{m}$ resolution. Also present at the SGP site is a microwave radiometer that measures the sky brightness temperatures at 23.8- and 31.4-GHz frequencies, from which the column-integrated water vapor (IWV) and liquid water path (LWP) were computed at 20-s resolution. A laser ceilometer at the SGP site operates at $905 \mathrm{~nm}$ recording cloud-base height and aerosol backscatter at a 15-s and 30-m resolution. The surface sensible heat flux (SHF) and latent heat flux (LHF) are recorded by an energybalance Bowen ratio station (EBBR) at 30-min resolution. The observations of SHF and LHF made by the eddy correlation flux measurement system (ECOR) are more representative of a larger area, while those from the EBBR correspond to point measurements (Brotzge and Crawford 2003). As the ECOR observations were not available for the entire period, we have used the EBBR observations. For a subset of the period, we used the observations of surface friction velocity $u^{*}$ from the ECOR. A radiation flux tower is also present at the SGP site that recorded the surface downwelling longwave (LW) and shortwave (SW) radiative fluxes.

\section{2) ARM GRACIOSA}

During the deployment of AMF-1 at the island of Graciosa (June 2009-December 2010), radiosondes were launched four times a day concurrent with the launch times at the SGP site. The AMF-1 is equipped with a vertically pointing $\mathrm{W}$-band cloud radar operating at $95-\mathrm{GHz}$ frequency [the W-band ARM cloud radar (WACR)]. The WACR recorded the first three moments of Doppler spectrum at 5-s and 42-m resolution, from which the cloud boundaries and filtered reflectivity were calculated. Similar to the SGP site, a laser ceilometer, a microwave radiometer, and a radiation flux platform were also part of the AMF-1 instrumentation deployed at GRW. Since the AMF-1 was located on an island, SHF and LHF as reported by the European Centre for Medium-Range Weather Forecasts (ECMWF) model were used for the GRW dataset. It should be noted that the ECMWF model-reported fluxes might differ from the reality but are still among the best available for this purpose (Brunke et al. 2011). Observations of $u^{*}$ as made by the ECOR system present on the island and part of the AMF-1 instrumentation were also used. We acknowledge that the $u^{*}$ values as simulated by reanalysis models (like ECMWF) might be more appropriate to use for the location, but they were not available for the period of study at GRW. We expect some influence of the island on these ECOR-measured $u^{*}$ values, but it is beyond the scope of this study to quantify the extent of the island effect on them.

\section{3) SOUTHEASTERn PACIFIC}

Annual month-long cruises were conducted in the southeastern Pacific by the NOAA ESRL's PSD nominally during the October-December period of each year (de Szoeke et al. 2012). The cruises began in October 2001 with the Eastern Pacific Investigation of Climate (EPIC) field campaign and were part of the VAMOS Ocean-Cloud-Atmosphere-Land Study Regional Experiment (VOCALS-REx) in 2008. During each cruise, radiosondes were launched six times per day when the ship was stationed at the Stratus Ocean Reference Station $\left(20^{\circ} \mathrm{S}, 85^{\circ} \mathrm{W}\right)$, which was typically for about a week. Also present on the ship during all the cruises was a ceilometer, a microwave radiometer, and radiation flux tower similar to the ARM sites. The surface SHF and LHF were measured as per the technique by Fairall et al. (2003) at 10-min resolution, from which the hourly averages were computed. Cloud radar was present on board the ship only during a few cruises, including EPIC, VOCALS, and Stratus 2004, but these data suffered from irreconcilable technical problems and hence were not used in this study.

\section{b. Case selection}

The analysis is based upon radiosonde data collected when single-layered stratocumulus clouds were observed an hour before and an hour after the radiosonde launch (three consecutive hours). The data collected by vertically pointing cloud radar and laser ceilometers at the ARM sites were used for identifying cloud structure. Additionally, events when the surface rain gauge detected any precipitation were also neglected. Because of the mesoscale structure of drizzle in stratocumulus cloud decks (Comstock et al. 2005, 2007), the presence of light drizzle and in-cloud drizzle in the selected cases cannot be ruled out. In the SEP region, we resorted to identifying stratocumulus with the laser ceilometer only, without the benefit of cloud radar data, and deemed the period acceptable when any 3 -h period revealed only a single cloud base and at least $90 \%$ cloud fraction. We find these criteria suitable, as previous observational studies from the SEP region have reported fewer occurrences of doublelayer stratocumulus clouds in this region (Ghate et al. 2009; Wood 2012), and none of the soundings exhibited more than one distinct layer with high $(>95 \%)$ relative humidity. At the ARM SGP and ARM GRW sites, events with in-cloud temperature lower than $-5^{\circ} \mathrm{C}$ were also neglected to constrain the analysis to warm stratocumulus clouds. 
TABLE 1. Location and number of radiosondes at each site.

\begin{tabular}{lccc}
\hline \hline & SEP & GRW & SGP \\
\hline Location & $20^{\circ} \mathrm{S}, 85^{\circ} \mathrm{W}$ & $39^{\circ} \mathrm{N}, 28^{\circ} \mathrm{W}$ & $36.5^{\circ} \mathrm{N}, 97.5^{\circ} \mathrm{W}$ \\
Years & 1 Oct $2000-31$ Oct 2008 & 1 Jun $2009-31$ Dec 2010 & 1 Jan $2001-31$ Dec 2010 \\
Total No. of sondes & 131 & 90 & 83 \\
DJF & $10(7.63 \%)$ & 0 & $26(31.32 \%)$ \\
MAM & 0 & 0 & $31(37.34 \%)$ \\
JJA & 0 & $62(68.88 \%)$ & $6(7.22 \%)$ \\
SON & $121(92.36 \%)$ & $28(31.11 \%)$ & $20(24.09 \%)$ \\
Daytime sondes $\mathrm{SWD}_{\text {sfc }}>100 \mathrm{~W} \mathrm{~m}^{-2}$ & $35(27 \%)$ & $38(42 \%)$ & $41(50 \%)$ \\
Nighttime sondes $\mathrm{SWD}_{\text {sfc }}=0 \mathrm{~W} \mathrm{~m}^{-2}$ & $81(61 \%)$ & $47(52 \%)$ & $26(31 \%)$ \\
Intermediate sondes $100>\mathrm{SWD}_{\text {sfc }}>0 \mathrm{~W} \mathrm{~m}^{-2}$ & $15(12 \%)$ & $5(6 \%)$ & $16(19 \%)$ \\
\hline
\end{tabular}

Subjecting 10 years of ARM SGP site data (2001-10) to the detection criteria yielded only 83 radiosonde profiles in STBL conditions. Plenty of STBL conditions were present in the data, but the requirement that all the instrumentation be operational during the period was the limiting factor. This low number of SGP cases was particularly surprising given that only 19 months of AMF GRW data provided 90 cases, and an even smaller number of months from the SEP region yielded 131 cases. The soundings were classified based on the seasons and as daytime, nighttime, or intermediate (twilight hours) based on the downwelling shortwave radiative flux (SWD) observed at the surface (Table 1). Most of the soundings from the SEP were from September to November (SON), as the cruises were conducted during that period. A clear message from the seasonal variation at GRW is the high occurrence of stratocumulus clouds during the summer [June-August (JJA)] and fall (SON) seasons, consistent with previous studies (Rémillard et al. 2012). At the SGP site, possibly because of strong surface forcing, very few cases are from JJA $(\sim 7 \%)$. While about $60 \%$ of the cases are from SON and MarchMay (MAM), consistent with the observations made by past studies that most of the stratocumulus clouds observed at the ARM SGP site are a result of frontal passages during spring and fall (e.g., Mechem et al. 2010; Ghate et al. 2010). On a percentage basis, the sampling bias is nearly a reciprocal for the SEP and SGP, with the latter being better sampled during the daytime. This distinction is particularly important, as the reported statistics of radiative fluxes and heating rates (Tables 2-4) are biased because of a high number of nighttime sondes at SEP and a high number of daytime sondes at the SGP site.

\section{Methodology}

Hourly averaged values of SHF, LHF, IWV, LWP, and radiative fluxes were computed along with the associated heating rates using the observational data and the output from the Rapid Radiative Transfer Model (RRTM). The lifting condensation level (LCL) height was calculated at each height for all the radiosondes using the formulation described by Bolton (1980). The lower-tropospheric stability (LTS), which is the difference between the potential temperature at $700 \mathrm{hPa}$ and that at the surface (Klein and Hartmann 1993), and the estimated inversion strength (EIS) per the formulation proposed by Wood and Bretherton (2006) were also calculated for each sounding.

The boundary layer inversion-base heights and inversiontop heights were determined from the temperature profiles using a technique similar to that employed by Abdul-Wahab (2003). The first layer of more than 20-m depth with an increase in temperature with height was identified as the inversion base, and the first height above the inversion base when the temperature decreased with height through the 20-m depth was termed the inversion top. Besides manually validating this approach, we consulted the cloud-top heights as observed by the cloud radars present at the SGP and GRW sites and found them to be consistent with our inversion-base heights. Our technique does not include any measure of humidity in determining the inversion boundaries, because the radiosonde humidity sensor may, on occasion, become wet while passing through the cloud layer.

The hourly averaged values of the SHF and LHF were used to compute the surface convective velocity scale $w_{\mathrm{sfc}}^{*}$ together with the inversion-base height $Z_{i}$, acceleration due to gravity $g$, and mean surface virtual potential temperature $\theta_{v}$ per the formulation proposed by Stull (1988):

$$
w_{\mathrm{sfc}}^{*}=\left[\frac{g Z_{i}}{\overline{\theta_{v}}}\left(\overline{w^{\prime} \theta_{v}^{\prime}}\right)_{\mathrm{sfc}}\right]^{1 / 3} .
$$

Given that stratocumuli are often driven by radiative cooling at cloud top, Lock and Macvean (1999) proposed a radiative velocity scale $w_{\text {rad }}^{*}$ that uses the radiative flux 
TABLE 2. Mean and standard deviation of different parameters at the three locations. At SGP, only 53 samples were used in calculating the statistics for $u^{*}$.

\begin{tabular}{|c|c|c|c|c|c|c|}
\hline & \multicolumn{2}{|c|}{ SEP } & \multicolumn{2}{|c|}{ GRW } & \multicolumn{2}{|c|}{ SGP } \\
\hline & Mean & Std dev & Mean & Std dev & Mean & Std dev \\
\hline$\theta_{v 1}-\theta_{v 0}$ & 0.28 & 0.31 & 0.53 & 0.48 & 0.29 & 0.88 \\
\hline$\theta_{v 2}-\theta_{v 1}$ & 0.52 & 0.72 & 0.39 & 0.62 & 0.20 & 1.17 \\
\hline$\theta_{v 3}-\theta_{v 2}$ & 0.25 & 0.35 & 0.14 & 0.36 & 0.38 & 1.51 \\
\hline Cloud top (m) & 1430 & 257 & 1283 & 365 & 1038 & 462 \\
\hline Cloud base (m) & 1107 & 279 & 1029 & 404 & 640 & 433 \\
\hline Cloud thickness (m) & 322 & 152 & 254 & 173 & 397 & 264 \\
\hline $\mathrm{LCL}_{\mathrm{sfc}}(\mathrm{m})$ & 732 & 205 & 710 & 274 & 448 & 226 \\
\hline $\operatorname{LWP}\left(\mathrm{g} \mathrm{m}^{-2}\right)$ & 139 & 83 & 163 & 281 & 118 & 80 \\
\hline IWV $(\mathrm{cm})$ & 1.64 & 0.36 & 2.92 & 1.31 & 1.71 & 0.89 \\
\hline $\operatorname{SHF}\left(\mathrm{W} \mathrm{m}^{-2}\right)$ & 9.41 & 6.8 & 7.89 & 8.9 & 31.94 & 51 \\
\hline $\operatorname{LHF}\left(\mathrm{W} \mathrm{m}^{-2}\right)$ & 103 & 29 & 71.57 & 46 & 35.82 & 40 \\
\hline Inversion $\Delta Z(\mathrm{~m})$ & 242 & 158 & 189 & 107 & 173 & 132 \\
\hline Inversion $\Delta \theta(\mathrm{K})$ & 11.70 & 2.84 & 6.52 & 2.66 & 6.89 & 4.31 \\
\hline Inversion $\Delta q(\mathrm{~K})$ & -5.43 & 1.48 & -3.69 & 2.21 & -0.41 & 1.59 \\
\hline Inversion $\Delta U\left(\mathrm{~m} \mathrm{~s}^{-1}\right)$ & -1.50 & 2.03 & 0.62 & 1.85 & 0.82 & 2.40 \\
\hline$\Delta \operatorname{SWF}\left(\mathrm{W} \mathrm{m}^{-2}\right)$ & 24.62 & 34.68 & 13.96 & 20.01 & 23.65 & 30.09 \\
\hline$\Delta \mathrm{LWF}\left(\mathrm{W} \mathrm{m}^{-2}\right)$ & -95.45 & 13.48 & -63.89 & 25.25 & -62.08 & 25.55 \\
\hline$\Delta F_{R}\left(\mathrm{~W} \mathrm{~m}^{-2}\right)$ & -70.27 & 34.99 & -49.93 & 29.29 & -38.42 & 34.92 \\
\hline$w_{\mathrm{sfc}}^{*}\left(\mathrm{~m} \mathrm{~s}^{-1}\right)$ & 0.68 & 0.26 & 0.58 & 0.28 & 0.71 & 0.60 \\
\hline$w_{\text {rad }}^{*}\left(\mathrm{~m} \mathrm{~s}^{-1}\right)$ & 1.32 & 0.35 & 1.15 & 0.29 & 0.88 & 0.44 \\
\hline$u^{*}\left(\mathrm{~m} \mathrm{~s}^{-1}\right)$ & 0.24 & 0.07 & 0.25 & 0.12 & 0.35 & 0.16 \\
\hline$w_{\mathrm{BR}}^{*}\left(\mathrm{~m} \mathrm{~s}^{-1}\right)$ & 0.13 & 0.28 & 0.14 & 0.26 & 0.02 & 0.11 \\
\hline$w^{*}\left(\mathrm{~m} \mathrm{~s}^{-1}\right)$ & 1.50 & 0.25 & 1.37 & 0.25 & 1.42 & 0.39 \\
\hline$w_{e}\left(\mathrm{~cm} \mathrm{~s}^{-1}\right)$ & 0.31 & 0.20 & 0.49 & 0.51 & 0.69 & 0.48 \\
\hline LTS (K) & 22.14 & 2.15 & 16.76 & 2.15 & 20.81 & 4.27 \\
\hline EIS (K) & 9.28 & 1.83 & 4.08 & 2.60 & 11.24 & 4.85 \\
\hline BWR & 1.66 & 1.04 & 3.02 & 3.30 & - & - \\
\hline
\end{tabular}

divergence across the cloud layer $\Delta F_{\text {rad }}$ and the inversionbase height along with the acceleration due to gravity $g$, density of air $\rho$, specific heat at constant pressure $c_{p}$, and boundary layer mean potential temperature $\theta$ :

$$
w_{\mathrm{rad}}^{*}=\left[\frac{g Z_{i}}{\rho c_{p} \bar{\theta}}\left(-\Delta F_{\mathrm{rad}}\right)\right]^{1 / 3} .
$$

Thus, Stull (1988) and Lock and Macvean (1999) are somewhat complementary, in that they characterize vertical transports driven from the two boundaries: the surface and the cloud top.

Lock et al. (2000) proposed a boundary layer parameterization to be used in GCMs that includes an explicit representation of the entrainment between different layers within the boundary layer. A similar construction was recently proposed by Bretherton and Park (2009). The Lock et al. (2000) entrainment rate parameterization is dependent on the velocity scale $w^{*}$, which is the cubic sum of the velocity scale due to surface heating, the velocity scale due to radiative cooling, the velocity scale due to buoyancy reversal $w_{\mathrm{BR}}^{*}$, and the friction velocity for the representation of shear:

$$
w^{* 3}=w_{\mathrm{sfc}}^{* 3}+w_{\mathrm{rad}}^{* 3}+w_{\mathrm{BR}}^{* 3}+25 u_{*}^{3} .
$$

Buoyancy reversal velocity scale is calculated near the cloud top and represents the entrainment of warm and dry air from above the inversion into the condensateladen saturated cloud layer generating negative buoyancy (or buoyancy reversal) because of phase change of the condensate. We have calculated $w_{\mathrm{BR}}^{*}$ using the technique proposed by Lock et al. (2000). The value of $w_{\mathrm{BR}}^{*}$ primarily depends on the jump in liquid water potential temperature and total water mixing ratio at the cloud top. As a result of a high level of uncertainty associated with retrieving the LWC near cloud top at high temporal resolution, hourly-mean profiles of LWC were used in computing the total water mixing ratio. Please refer to the appendix in Lock et al. (2000) for a detailed explanation on calculating $w_{\mathrm{BR}}^{*}$ and the other constants.

This also presented an opportunity to calculate the entrainment rate using Lock et al.'s (2000) parameterization, which uses the radiative flux divergence across the cloud layer $\Delta F_{R}$, the lifting condensation level from surface measurements $\left(\mathrm{LCL}_{\mathrm{sfc}}\right)$, and the buoyancy jump near cloud top $\Delta b$ : 


$$
w_{e}=A_{1} \frac{\left(w^{* 3} / \mathrm{LCL}_{\mathrm{sfc}}\right)+g \tilde{\beta}_{T} \alpha_{t} \Delta F_{R}}{\Delta b+\left(C_{T} w^{* 2} / \mathrm{LCL}_{\mathrm{sfc}}\right)} .
$$

In this study, we have used the same values of the constants in the above equation and in the equations of $w_{\mathrm{BR}}^{*}$ and $\Delta b$ as used by Lock et al. (2000). Although we are reporting the calculated entrainment rate $\left(\mathrm{cm} \mathrm{s}^{-1}\right)$, the values are reported for studying their variations across different regions and thermodynamic conditions. It is beyond the scope of this study to validate the calculated entrainment rate using the above equation. This issue is discussed further in the summary and discussion section.

Bretherton and Wyant (1997) proposed a decoupling criteria based upon simulations conducted on idealized steady-state, nonprecipitating well-mixed stratocumulus clouds. Their criteria was later modified by Jones et al. (2011) to be

$$
\frac{\Delta F_{R}}{\mathrm{LHF}}<A \eta \frac{\Delta Z_{M}}{Z_{i}}
$$

where LHF is the latent heat flux at the surface, $A$ is the entrainment efficiency, $\eta$ is a thermodynamic variable, $Z_{i}$ is the boundary layer (BL) inversionbase height, and $\Delta Z_{M}$ is the distance between surface LCL height and the BL inversion-base height, which corresponds to the depth of the cloud layer if the $\mathrm{BL}$ is well mixed. To evaluate this criterion, we use the ratio of the two sides of the above equation and term it the Bretherton-Wyant ratio (BWR). It is written as

$$
\mathrm{BWR}=\frac{\Delta F_{R}}{\mathrm{LHF}} \frac{Z_{i}}{A \eta \Delta Z_{M}} .
$$

Hence, decoupling should occur for BWR $<1$, while for BWR $>1$, the boundary layer is expected to be well mixed and coupled to the surface. We have assumed $A=$ 1.1 and $\eta=0.9$ based on Jones et al. (2011) and Caldwell et al. (2005). In essence, this assumption allows the relationship between the STBL boundary conditions and the relative location of the LCL to uniquely determine the decoupling condition. It should be noted that some transport from the surface to the cloud layer is still present, as updrafts spanning through the entire depth of the boundary layer were reported by Ghate et al. (2014) during both coupled and decoupled conditions.

\section{General characteristics}

The mean and standard deviations of the variables associated with the STBL are reported in Table 2. To gauge the profile of virtual potential temperature, the differences between the four different points used in the averaging procedure are also listed. On average, the difference between the cloud base and surface virtual potential temperature $\left(\theta_{v 3}-\theta_{v 0}\right)$ is about $1 \mathrm{~K}$ at all three locations. The variability (standard deviations) in the temperature differences is highest at the SGP. It should be noted that the standard deviations of these values are either equal to or greater than the mean values. Below we have discussed the contrast between the two marine locations (SEP and GRW), followed by a description on how the STBLs observed at the SGP site differ from those at the marine locations. Below and in the rest of the paper, we have only discussed parameters that either showed statistically significant differences among the sites or were expected to statistically differ but did not. The $t$ values signifying the statistical significance of the differences in the variables at the locations are reported in the supplemental material.

The STBL over SEP was deeper than at GRW, with average cloud-top heights of $1430 \mathrm{~m}$ at SEP and $1283 \mathrm{~m}$ at GRW. The stratocumulus clouds over SEP were also thicker (322 m) than those over GRW (254 m). Despite statistically significant differences in cloud thicknesses at the two locations, there were no significant differences in LWP. The IWV value was almost twice as much at GRW as its value at SEP. This is mainly due to the higher upper-tropospheric moisture present at GRW, as compared to that over SEP. Although the contrast in SHF was not statistically significant, the LHF was much higher over SEP $\left(103 \mathrm{~W} \mathrm{~m}^{-2}\right)$, as compared to that over GRW $\left(71.57 \mathrm{~W} \mathrm{~m}^{-2}\right)$. The inversion thickness together with the strength of the inversion in terms of jump in potential temperature, mixing ratio, and wind speed was higher for STBL over SEP, as compared to those over GRW. The stronger and deeper inversion together with thicker clouds and lower free-tropospheric water vapor also meant much higher radiative flux divergence across the cloud layer at SEP compared to GRW. The LW radiative flux divergence across the cloud layer at SEP was about $-95 \mathrm{~W} \mathrm{~m}^{-2}$, as compared to about $-63 \mathrm{~W} \mathrm{~m}^{-2}$ over GRW, while the net radiative flux divergence across the cloud layer was about $-70 \mathrm{Wm}^{-2}$ over SEP and about $-50 \mathrm{~W} \mathrm{~m}^{-2}$ over GRW. With the exception of buoyancy reversal velocity scale and friction velocity, the velocity scales were significantly higher for STBL over SEP than for STBL over GRW. As the STBL depth is one of the parameters in the formulation of the velocity scales, greater STBL depth at SEP was partly responsible for the higher values of velocity scales over SEP, as compared to those over GRW. The entrainment velocity $w_{e}$ was higher over GRW $\left(0.49 \mathrm{~m} \mathrm{~s}^{-1}\right)$ than over SEP $\left(0.31 \mathrm{~m} \mathrm{~s}^{-1}\right)$, partly because of weaker inversion. LTS and EIS were higher at SEP than over GRW, with the EIS value at 

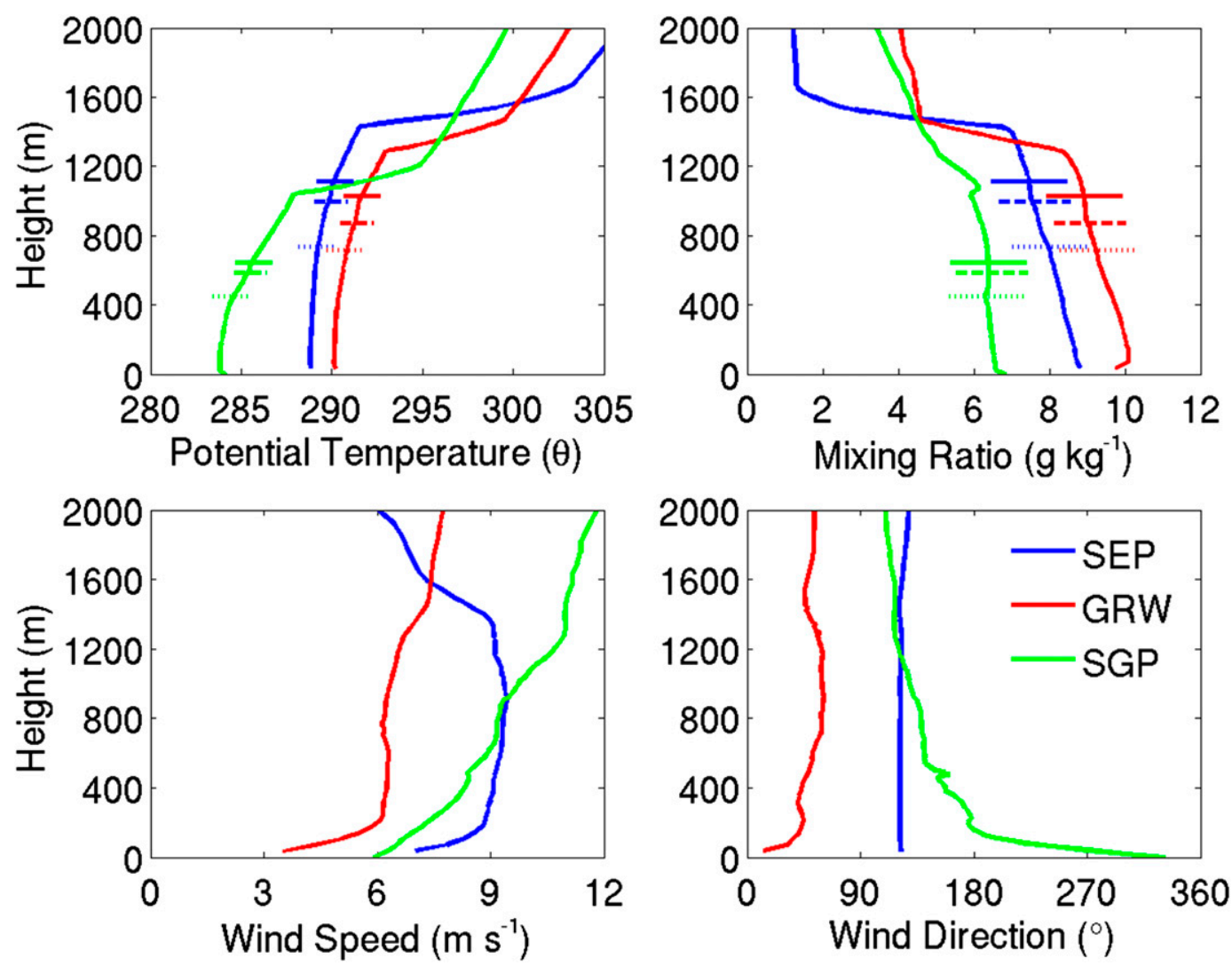

FIG. 1. Averaged profiles of potential temperature, mixing ratio, wind speed, and wind direction at the three locations under STBL conditions. The dotted, dashed, and solid horizontal lines denote the averaged $\mathrm{LCL}_{\mathrm{sfc}}, \mathrm{LCL}_{\mathrm{CB}}$, and cloud-base height, respectively.

SEP (9.28 K) being more than double that over GRW $(4.08 \mathrm{~K})$. The BWR is greater than unity at both the locations, while the value at GRW is much higher (3.02), as compared to that over SEP (1.66). This suggests that, according to the decoupling criteria, the STBLs over both of these locations are well mixed, with the degree of "well mixedness" being much higher over GRW than over SEP.

Compared to the STBLs over GRW, the STBLs over SGP were shallower and had thicker clouds with an average cloud thickness of about $400 \mathrm{~m}$. The LWP values at all the locations didn't exhibit any significant differences between each other; this is surprising, considering the differences in the BL depth and surface conditions between the locations. Because of its continental location, the surface SHF was much higher over SGP $\left(31.94 \mathrm{~W} \mathrm{~m}^{-2}\right)$ than over GRW $\left(7.89 \mathrm{~W} \mathrm{~m}^{-2}\right)$. The inversion strength in terms of jump in water vapor mixing ration was lowest over the SGP $\left(-0.41 \mathrm{~g} \mathrm{~kg}^{-1}\right)$ and highest over the SEP $\left(-5.43 \mathrm{~g} \mathrm{~kg}^{-1}\right)$. Similarly, $w_{\text {rad }}^{*}$ was also lowest over the SGP $\left(0.88 \mathrm{~m} \mathrm{~s}^{-1}\right)$ and highest over the SEP $\left(1.32 \mathrm{~m} \mathrm{~s}^{-1}\right)$. The entrainment rate was highest over SGP $\left(0.69 \mathrm{~m} \mathrm{~s}^{-1}\right)$ and lowest over the SEP $\left(0.31 \mathrm{~m} \mathrm{~s}^{-1}\right)$, with a value of $0.49 \mathrm{~m} \mathrm{~s}^{-1}$ over GRW. The LTS was highest over SEP and lowest over GRW, while the EIS was highest over SGP and lowest over GRW. Both the LTS and EIS differed by less than $2 \mathrm{~K}$ between SEP and SGP STBLs.

The profiles of potential temperature, mixing ratio, wind speed, and wind direction were averaged using the new proposed averaging procedure at the three locations and are shown in Fig. 1. Potential temperature beneath the inversion is much lower at SGP than at SEP and GRW because stratocumuli are generally associated with cold frontal passage at that location. All three locations exhibit similar thermal structure, in which the potential temperature is nearly similar from the surface to the $\mathrm{LCL}_{\mathrm{sfc}}$ and increases thereafter. Substantial negative vertical gradients in mixing ratio are present below the cloud layer in the GRW and SEP soundings, but not at SGP. In that location, the mixing ratio is nearly constant with height throughout the boundary layer, and there is a gradual decrease in mixing ratio from boundary layer to the free troposphere, as opposed to the abrupt mixing ratio gradients above the cloud top over the SEP and at GRW.

There is negligible speed and directional wind shear in the SEP and GRW soundings above about $200 \mathrm{~m}$ but significant speed and directional shear in the entire SGP 

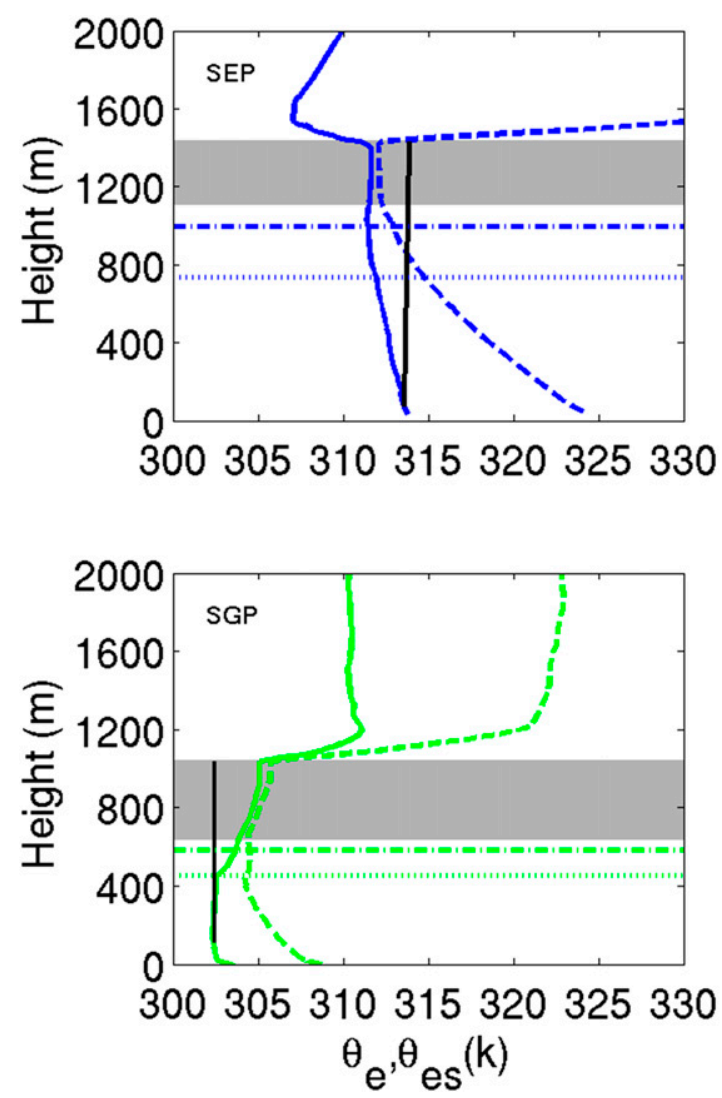

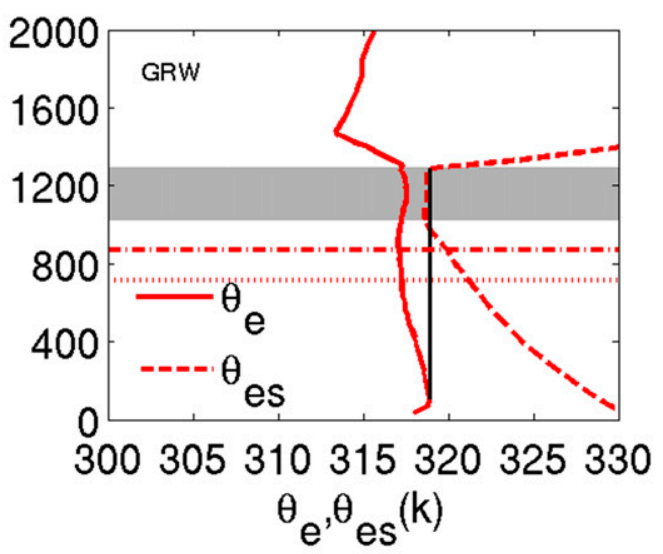

FIG. 2. Averaged profile of equivalent potential temperature and saturated equivalent potential temperature at the three locations. The gray shaded area indicates the physical location of the cloud, the dotted-dashed horizontal line denotes the $\mathrm{LCL}_{\mathrm{CB}}$ and the dashed horizontal line denotes the average $\mathrm{LCL}_{\text {sfc }}$. The solid vertical black line denotes the equivalent potential temperature at $100-\mathrm{m}$ height. profile. The SGP soundings exhibit a strong directional wind shear, with northerly winds at the surface and southerly winds in the upper part of the boundary layer, which suggests that most of the stratocumuli identified in this study were associated with a frontal system. The averaged large-scale vertical air motion at $700 \mathrm{hPa}$ (not shown) as reported by the ECMWF reanalysis model was positive (denoting downward motion) at the marine locations, while it was negative (denoting upward motion) for about half of the soundings over the SGP. This alludes to the possibility that the stratocumulus clouds over the SGP are part of the frontal zone itself and may be associated with overrunning.

Viewing the data in Fig. 1 holistically, the averaged profiles at the marine sites are remarkably similar to sounding examples shown by modeling studies (Zhu et al. 2005; Stevens et al. 2005) and observational studies (Serpetzoglou et al. 2008; Miller and Albrecht 1995; etc.). In contrast, the STBL at SGP is shallow relative to the marine locations, possesses more wind shear, and is observed in a synoptic regime that, according to the ECMWF reanalysis data, experienced uplift in few cases. These observations lie in contrast to conventional wisdom (Mechem et al. 2010), which favors postfrontal stratocumuli.
Conserved variable analysis can illuminate differences in the physical processes that formed sublayers within the boundary layer. Figure 2 shows the averaged profiles of equivalent potential temperature $\theta_{e}$ and saturation equivalent potential temperature $\theta_{e s}$ for the three locations. The $\theta_{e}$ profile over the SEP indicates weakly unstable conditions from the surface to the $\mathrm{LCL}_{\mathrm{CB}}$ and neutral to slightly stable conditions from the $\mathrm{LCL}_{\mathrm{CB}}$ to cloud top. So from the $\mathrm{LCL}_{\mathrm{CB}}$ upward in the SEP boundary layer, convection initiated from below and, reaching this level, will meet with little or no resistance as it rises to the base of the inversion. Energy to support this convection over the SEP is supplied by convective available potential energy (CAPE). Lifting a parcel at $100 \mathrm{~m}$ until it reaches $\theta_{e s}$ demonstrates that there is significant CAPE present in the STBL over SEP. Because our averaging procedure preserves the $\theta_{e}$ and $\theta_{e s}$ values of individual layers and their thicknesses, chances are increased that the CAPE calculated from the averaged sounding would match the average of the CAPEs calculated from individual soundings. The convective inhibition (CIN) calculated from the mean soundings was $-59.53 \mathrm{~m}^{2} \mathrm{~s}^{-2}$ over SEP and $-58.69 \mathrm{~m}^{2} \mathrm{~s}^{-2}$ over GRW. While the CAPE calculated from the mean soundings was $13.5 \mathrm{~m}^{2} \mathrm{~s}^{-2}$ over SEP and $1.03 \mathrm{~m}^{2} \mathrm{~s}^{-2}$ over GRW. 

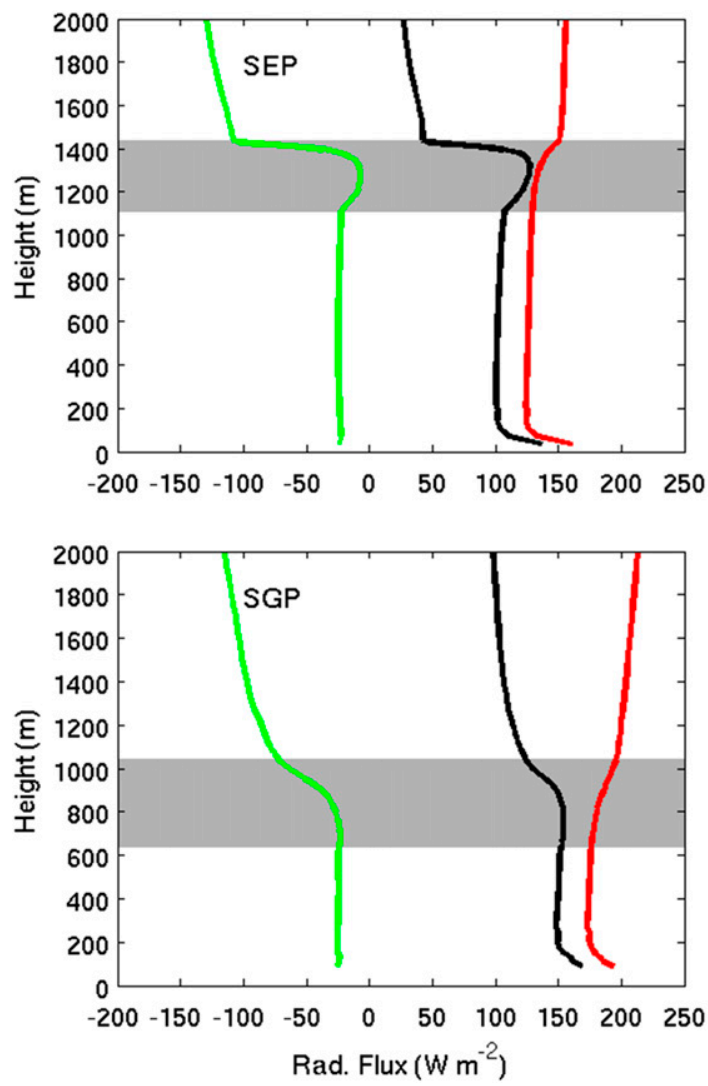

While the vertical profiles of $\theta_{e}$ and $\theta_{e s}$ over the SEP and at GRW look similar in shape, the cloud layer at GRW is the shallowest of the three locations, and there is little CAPE. Some caution must be exercised in interpreting this result, however, because $\theta_{e}$ and $\theta_{e s}$ did not have the same value in the cloud layer over GRW. While this could be a result of bad humidity sensors on the radiosondes, it is more likely a result of mesoscale variability in the cloud layer. Dry intrusions of inversion air associated with thinning clouds were noted in this region in a previous study (Wang and Albrecht 1994). Comparatively speaking, the continental stratocumuli observed at SGP exhibit radically different vertical structure. The SGP composite sounding is neutrally stable from surface to the $\mathrm{LCL}_{\mathrm{sfc}}$ and stable above that. There is no convective instability anywhere in the SGP sounding, because $\theta_{e}$ increases with height above the $\mathrm{LCL}_{\mathrm{sfc}}$, even in the boundary layer inversion, unlike in the GRW and SEP soundings. During only 3 soundings out of 83 , the $\theta_{e}$ decreased with height near the STBL inversion over the SGP. This also contributed to the $w_{\mathrm{BR}}^{*}$ being nonzero only for three soundings over the SGP. The free troposphere was convectively stable with height at GRW and SEP, but it is almost neutral over SGP.

The radiative fluxes calculated using RRTM were also averaged using the proposed averaging procedure and

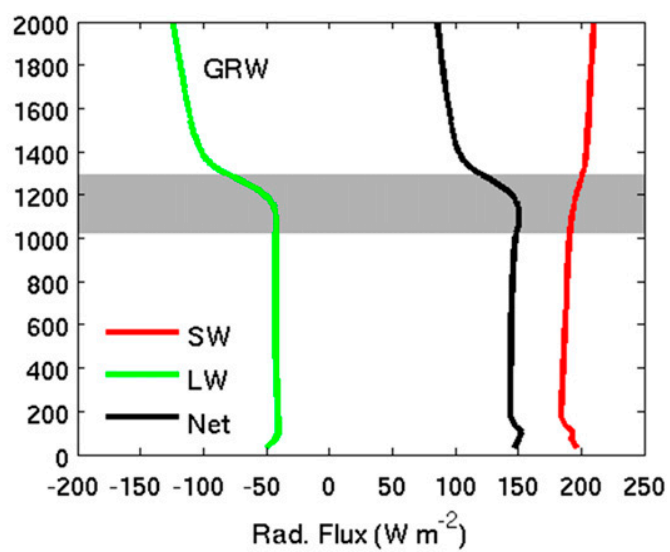

FIG. 3. Averaged profile of shortwave (SW), longwave (LW), and net radiation flux over the three sites. The shaded area denotes the averaged cloud location at the sites.

are shown in Fig. 3. Note that when interpreting the SW and net radiative fluxes over the different locations, the number of daytime and nighttime soundings must be considered (Table 1). The LW radiative flux in the subcloud layer was about $-25 \mathrm{~W} \mathrm{~m}^{-2}$ over the SEP and SGP and double this value $\left(-50 \mathrm{~W} \mathrm{~m}^{-2}\right)$ over GRW. Lower surface temperatures over the SGP and lower LWPs over GRW contribute to the weak cloud-base heating computed there relative to over the SEP. Also, the RRTM simulations were made at 5- and 10-s resolution for GRW and the SGP, respectively, which were then averaged to produce hourly profiles. As the cloud thickness varies within the hour and the increase in LW flux near cloud base is small, the radiative heating near cloud base is smeared across a range of depths, masking individual peaks. The averaged SW radiative flux in the subcloud layer is about $125 \mathrm{~W} \mathrm{~m}^{-2}$ over the SEP and about $180 \mathrm{~W} \mathrm{~m}^{-2}$ at GRW and over the SGP. As expected, the net SW flux increases with height in the subcloud layer with a sharp increase in the cloud layer. Above the inversion, the net SW flux barely increases with height in the lower free troposphere. The net radiative flux in the boundary layer is, on average, positive at all locations despite the presence of stratocumuli, with a value of about $100 \mathrm{~W} \mathrm{~m}^{-2}$ over SEP and about $150 \mathrm{~W} \mathrm{~m}^{-2}$ over GRW and SGP. 

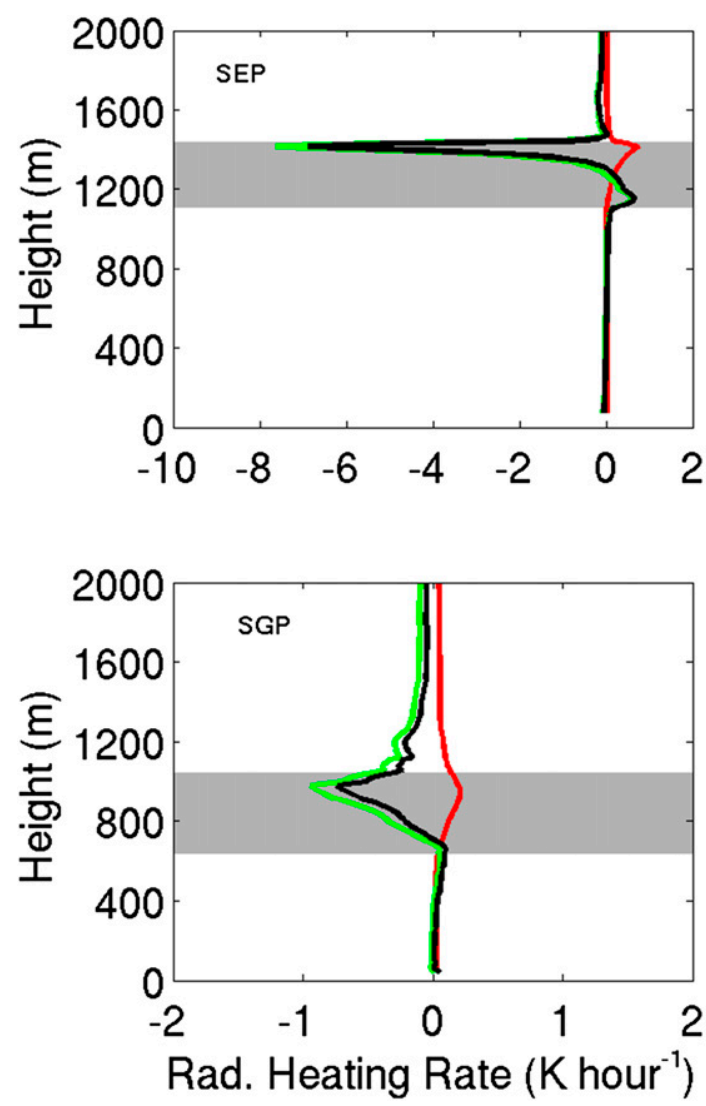

The $\mathrm{LW}$, SW, and net radiative heating rates were computed using the radiative flux divergence at each level and are shown in Fig. 4. The LW radiative cooling near cloud top over the SEP was about $-7 \mathrm{Kh}^{-1}$, while it was about $-1 \mathrm{Kh}^{-1}$ over GRW and the SGP. These larger values are consistent with those reported in Moeng et al. (1996) for the marine clouds. Greater cooling rates computed over the SEP are mainly due to the low amount of water vapor in the free troposphere and a higher jump in mixing ratio across the inversion. We would like to acknowledge that the sharp LW radiative cooling profile over SEP compared to that over SGP and GRW could be due to the adiabatic LWC assumption made in that region. The LW radiative heating at cloud base is about $0.5 \mathrm{~K} \mathrm{~h}^{-1}$ at SEP and about $0.05 \mathrm{~K} \mathrm{~h}^{-1}$ over GRW and SGP.

The averaged SW radiative heating rate is negligible when compared to the LW cooling rate in all locations. Most importantly, the net radiative heating rate loosely follows the profile of the $\mathrm{LW}$ radiative heating rates at all three locations. Radiative cooling rates over the SEP are strikingly larger than over GRW and SGP. A potential contributor to this difference may be the absence of synoptic-scale features commonly seen over GRW (Rémillard et al. 2012) and over the SGP (Kollias et al. 2007), which bring high-level clouds and humidity to the

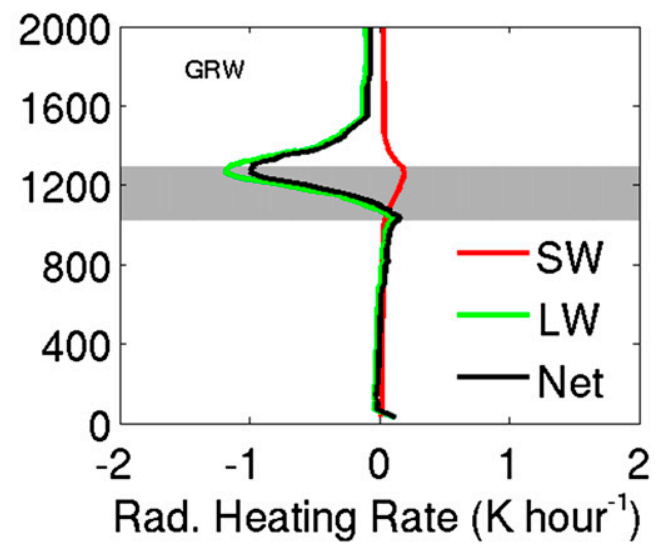

FIG. 4. Averaged profile of shortwave, longwave, and net radiative heating rates at the three locations. The shaded area denotes the averaged cloud location at the sites.

regions. Net heating at cloud base over the SEP, combined with exceptionally strong net cooling at cloud top, implies that the contribution of radiation to the in-cloud turbulence over the SEP might be quite different compared to the same at other locations.

\section{STBL thermodynamic modes}

Different modes are known to exist in the STBL when it is devoid of cumulus clouds (Norris 1998). Several of these modes are shown schematically by Lock et al. (2000) and are individually parameterized (Fig. B1). Four of these modes are 1) well mixed, 2) stable, 3) a stable surface layer with a mixed layer above it, and 4) a classic decoupled boundary layer consisting of two well-mixed layers and a transition layer. We discovered an additional mode consisting of a well-mixed layer near surface overlaid by a stable layer that extended to the cloud base (Fig. B1). We refer to this additional structure as 5) well-mixed plus stable mode.

We analyzed the STBL soundings and discovered that three of the modes listed above were dominant $(1,2$, and 5 above). In addition to these three modes, mode 3 was observed once over the SEP and the SGP and in three soundings over GRW. Mode 4 was observed in five 
soundings over the SEP and the SGP and in six soundings in GRW. Neither mode 3, nor mode 4 was observed frequently enough to provide a robust statistical sample. We believe that mode 5 and mode 3 are separate, with mode 5 being a result of cooling due to drizzle evaporation and mode 3 being a result of a combination of factors, including reduction in cloud-top radiative cooling and drizzle evaporative cooling. Scatterplots between conserved variables like total water mixing ratio and equivalent potential temperature for the five modes will help illuminate the role of different processes in creating/maintaining the respective thermodynamic structure (Betts and Albrecht 1987). As we lack the number of samples needed to perform a conserved variable analysis, we have classified the soundings as well mixed or decoupled using the following criteria, which uses the difference between the surface virtual potential temperature and the virtual potential temperature at the cloud base:

$$
\begin{gathered}
\left|\theta_{v 3}-\theta_{v 0}\right|<0.25 \mathrm{~K}: \text { Well-mixed STBL } \\
\theta_{v 3}-\theta_{v 0}>1 \mathrm{~K}: \text { Decoupled STBL }
\end{gathered}
$$

This sounding classification is not exhaustive and is similar to that proposed by Jones et al. (2011), Yin and Albrecht (2000), and Serpetzoglou et al. (2008). The STBL classified as well mixed correspond to the mode 1, while those classified as decoupled correspond to the rest of the modes. It is beyond the scope of this study to further classify the decoupled STBLs into the different modes listed above. The averaged values of the boundary layer parameters for different STBL configurations at the three locations are reported in Tables 3-5 for SEP, GRW and SGP, respectively.

\section{a. Southeastern Pacific}

According to the classification described above, when applied to the SEP dataset, 31 soundings $(24 \%)$ were identified as well mixed, and 54 soundings $(41 \%)$ were identified as decoupled. The profiles of virtual potential temperature, mixing ratio, wind speed, and radiative heating rate for the distinction are shown in Fig. 5. Also shown are the profiles of $\theta_{e}$ and $\theta_{e s}$ for the distinction. The mean values of STBL parameters, along with their standard deviations for the thermodynamic classification are reported in Table 3, together with $t$ value of statistical significance.

The boundary layer was deeper during decoupled conditions, with the differences between the cloud-base and cloud-top heights for the distinction being statistically significant. Although the BL was deeper, the $\mathrm{LCL}_{\text {sfc }}$ was significantly lower during decoupled conditions than during well-mixed conditions. Consistent with
TABLE 3. General characteristics of well-mixed and decoupled STBLs at the SEP site. The critical $|t|$ value for the $95 \%$ confidence

\begin{tabular}{|c|c|c|c|c|c|}
\hline & \multicolumn{2}{|c|}{ Well mixed } & \multicolumn{2}{|c|}{ Decoupled } & $|t|$ \\
\hline \multirow[t]{2}{*}{ No. of sondes } & \multicolumn{2}{|c|}{31} & \multicolumn{2}{|c|}{54} & \\
\hline & \multicolumn{2}{|c|}{$4(13 \%)$} & \multicolumn{2}{|c|}{$22(40 \%)$} & \\
\hline Daytime sondes & Mean & Std dev & Mean & Std dev & \\
\hline$\theta_{v 1}-\theta_{v 0}(\mathrm{~K})$ & 0.01 & 0.11 & 0.46 & 0.32 & 9.41 \\
\hline$\theta_{v 2}-\theta_{v 1}(\mathrm{~K})$ & 0.13 & 0.17 & 0.99 & 0.91 & 6.74 \\
\hline$\theta_{v}-\theta_{v 2}(\mathrm{~K})$ & 0.04 & 0.08 & 0.44 & 0.44 & 6.49 \\
\hline Cloud base (m) & 925 & 127 & 1223 & 332 & 5.88 \\
\hline Cloud top (m) & 1255 & 136 & 1572 & 274 & 7.11 \\
\hline $\begin{array}{l}\text { Cloud } \\
\text { thickness (m) }\end{array}$ & 329 & 122 & 348 & 187 & 0.56 \\
\hline $\mathrm{LCL}_{\mathrm{sfc}}(\mathrm{m})$ & 803 & 115 & 664 & 225 & 3.76 \\
\hline $\operatorname{LWP}\left(\mathrm{g} \mathrm{m}^{-2}\right)$ & 158 & 76 & 138 & 85 & 1.11 \\
\hline IWV $(\mathrm{cm})$ & 1.47 & 0.19 & 1.69 & 0.40 & 3.42 \\
\hline $\operatorname{SHF}\left(\mathrm{W} \mathrm{m}^{-2}\right)$ & 10.60 & 6.73 & 10.89 & 6.43 & 0.19 \\
\hline $\operatorname{LHF}\left(\mathrm{W} \mathrm{m}^{-2}\right)$ & 104.54 & 22.01 & 103.37 & 33.31 & 0.19 \\
\hline $\begin{array}{l}\text { Inversion } \\
\Delta \theta(\mathrm{K})\end{array}$ & 13.60 & 2.75 & 10.87 & 2.52 & 4.54 \\
\hline $\begin{array}{l}\text { Inversion } \\
\qquad \Delta q\left(\mathrm{~g} \mathrm{~kg}^{-1}\right)\end{array}$ & -5.78 & 1.10 & -5.08 & 1.69 & 2.30 \\
\hline $\begin{array}{l}\text { Inversion } \\
\Delta Z(\mathrm{~m})\end{array}$ & 310 & 200 & 233 & 146 & 1.87 \\
\hline $\begin{array}{l}\text { Inversion } \\
\qquad \Delta U\left(\mathrm{~m} \mathrm{~s}^{-1}\right)\end{array}$ & -1.22 & 1.52 & -1.65 & 2.40 & 1.01 \\
\hline$\Delta \operatorname{SWF}\left(\mathrm{W} \mathrm{m}^{-2}\right)$ & 12.50 & 22.07 & 37.01 & 40.99 & 3.58 \\
\hline$\Delta \mathrm{LWF}\left(\mathrm{W} \mathrm{m}^{-2}\right)$ & -94.19 & 12.29 & -99.38 & 13.77 & 1.79 \\
\hline$\Delta F_{R}\left(\mathrm{~W} \mathrm{~m}^{-2}\right)$ & -81.69 & 22.79 & -62.36 & 41.37 & 2.77 \\
\hline$w_{\mathrm{sfc}}^{*}\left(\mathrm{~m} \mathrm{~s}^{-1}\right)$ & 0.70 & 0.20 & 0.77 & 0.21 & 1.52 \\
\hline$w_{\mathrm{rad}}^{*}\left(\mathrm{~m} \mathrm{~s}^{-1}\right)$ & 1.39 & 0.17 & 1.26 & 0.44 & 1.93 \\
\hline$u^{*}\left(\mathrm{~m} \mathrm{~s}^{-1}\right)$ & 0.22 & 0.08 & 0.26 & 0.07 & 2.32 \\
\hline$w_{\mathrm{BR}}^{*}\left(\mathrm{~m} \mathrm{~s}^{-1}\right)$ & 0.08 & 0.19 & 0.13 & 0.29 & 0.95 \\
\hline$w^{*}\left(\mathrm{~m} \mathrm{~s}^{-1}\right)$ & 1.51 & 0.17 & 1.49 & 0.31 & 0.38 \\
\hline$w_{e}\left(\mathrm{~cm} \mathrm{~s}^{-1}\right)$ & 0.23 & 0.08 & 0.37 & 0.26 & 3.66 \\
\hline LTS (K) & 24.99 & 0.71 & 23.44 & 1.99 & 5.17 \\
\hline EIS (K) & 13 & 0.91 & 11.04 & 1.63 & 7.11 \\
\hline BWR & 2.44 & 0.88 & 1.09 & 0.71 & 7.28 \\
\hline
\end{tabular}
interval is 2.03 .

deeper BL, the IWV was higher during decoupled conditions than during well-mixed conditions. Contrary to expectations, there were no significant differences between the cloud thickness, LWP, SHF, and LHF for the classification at SEP. There were significant differences in the inversion strengths between the decoupled and well-mixed soundings, with the jump in potential temperature and mixing ratio being greater during wellmixed conditions. This is consistent with the hypothesis of stratocumulus cloud breakup during a weaker inversion, as proposed by Lock (2009). Although the LW radiative cooling at the cloud top was similar for the classification, the changes in the SW and net radiative flux divergences across the cloud layer were significant, with greater radiative cooling near cloud top during well-mixed conditions. The surface friction velocity was higher during well-mixed conditions than during 
TABLE 4. General characteristics of well-mixed and decoupled STBLs at the GRW site. The critical $|t|$ value for $95 \%$ confidence interval is 2.16 .

\begin{tabular}{|c|c|c|c|c|c|}
\hline & \multicolumn{2}{|c|}{ Well mixed } & \multicolumn{2}{|c|}{ Decoupled } & $|t|$ \\
\hline No. of sondes & & & & & \\
\hline \multirow[b]{2}{*}{ Daytime sondes } & \multicolumn{2}{|c|}{$6(46 \%)$} & \multicolumn{2}{|c|}{$18(41 \%)$} & \\
\hline & Mean & Std dev & Mean & Std dev & \\
\hline$\theta_{v 1}-\theta_{v}(\mathrm{~K})$ & 0.04 & 0.10 & 0.86 & 0.47 & 10.66 \\
\hline$\theta_{v 2}-\theta_{v 1}(\mathrm{~K})$ & 0.03 & 0.03 & 0.78 & 0.71 & 6.90 \\
\hline$\theta_{v 3}-\theta_{v 2}(\mathrm{~K})$ & 0.05 & 0.06 & 0.56 & 0.40 & 8.06 \\
\hline Cloud base (m) & 754 & 336 & 1217 & 348 & 4.31 \\
\hline Cloud top (m) & 1000 & 319 & 1486 & 296 & 4.89 \\
\hline $\begin{array}{l}\text { Cloud } \\
\text { thickness (m) }\end{array}$ & 245 & 144 & 268 & 185 & 0.47 \\
\hline $\mathrm{LCL}_{\mathrm{sfc}}(\mathrm{m})$ & 752 & 320 & 657 & 225 & 0.99 \\
\hline $\operatorname{LWP}\left(\mathrm{g} \mathrm{m}^{-2}\right)$ & 81 & 53 & 132 & 171 & 1.70 \\
\hline IWV $(\mathrm{cm})$ & 2.27 & 0.76 & 3.40 & 1.42 & 3.73 \\
\hline $\operatorname{SHF}\left(\mathrm{W} \mathrm{m}^{-2}\right)$ & 13.55 & 14.63 & 5.94 & 6.77 & 1.81 \\
\hline $\operatorname{LHF}\left(\mathrm{W} \mathrm{m}^{-2}\right)$ & 90.15 & 62.14 & 65.44 & 37.97 & 1.35 \\
\hline $\begin{array}{c}\text { Inversion } \\
\Delta \theta(\mathrm{K})\end{array}$ & 7.01 & 2.43 & 5.84 & 2.37 & 1.52 \\
\hline $\begin{array}{l}\text { Inversion } \\
\qquad \Delta q\left(\mathrm{~g} \mathrm{~kg}^{-1}\right)\end{array}$ & -3.64 & 2.08 & -3.80 & 2.19 & 0.24 \\
\hline $\begin{array}{r}\text { Inversion } \\
\Delta Z(\mathrm{~m})\end{array}$ & 159 & 114 & 165 & 95 & 0.17 \\
\hline $\begin{array}{l}\text { Inversion } \\
\qquad \Delta U\left(\mathrm{~m} \mathrm{~s}^{-1}\right)\end{array}$ & 0.15 & 1.43 & -0.03 & 1.58 & 0.38 \\
\hline$\Delta \mathrm{SWF}\left(\mathrm{W} \mathrm{m}^{-2}\right)$ & 13.13 & 13.71 & 13.85 & 20.74 & 0.14 \\
\hline$\Delta \mathrm{LWF}\left(\mathrm{W} \mathrm{m}^{-2}\right)$ & -69.22 & 24.87 & -66.49 & 22.85 & 0.35 \\
\hline$\Delta F_{R}\left(\mathrm{~W} \mathrm{~m}^{-2}\right)$ & -56.09 & 23.35 & -52.64 & 24.95 & 0.45 \\
\hline$w_{\mathrm{sfc}}^{*}\left(\mathrm{~m} \mathrm{~s}^{-1}\right)$ & 0.66 & 0.33 & 0.55 & 0.28 & 1.08 \\
\hline$w_{\text {rad }}^{*}\left(\mathrm{~m} \mathrm{~s}^{-1}\right)$ & 1.13 & 0.25 & 1.24 & 0.21 & 1.44 \\
\hline$u^{*}\left(\mathrm{~m} \mathrm{~s}^{-1}\right)$ & 0.31 & 0.13 & 0.24 & 0.12 & 1.73 \\
\hline$w_{\mathrm{BR}}^{*}\left(\mathrm{~m} \mathrm{~s}^{-1}\right)$ & 1.10 & 1.14 & 0.22 & 0.34 & 2.74 \\
\hline$w^{*}\left(\mathrm{~m} \mathrm{~s}^{-1}\right)$ & 1.41 & 0.22 & 1.43 & 0.21 & 0.29 \\
\hline$w_{e}\left(\mathrm{~cm} \mathrm{~s}^{-1}\right)$ & 0.50 & 0.44 & 0.58 & 0.49 & 0.55 \\
\hline LTS (K) & 18.81 & 2.71 & 18.92 & 1.88 & 0.13 \\
\hline EIS (K) & 7.20 & 3.23 & 6.09 & 2.15 & 1.16 \\
\hline BWR & 3.98 & 4.33 & 1.28 & 7.21 & 1.65 \\
\hline
\end{tabular}

decoupled conditions, while the other velocity scales $\left(w_{\mathrm{sfc}}^{*}, w_{\mathrm{rad}}^{*}, w_{\mathrm{BR}}^{*}\right.$, and $\left.w^{*}\right)$ did not exhibit a statistically significant difference for the classification. Although difficult to interpret, the differences between the entrainment rate during well-mixed and decoupled conditions were statistically significant, with the entrainment rate being higher $\left(0.26 \mathrm{~m} \mathrm{~s}^{-1}\right)$ during decoupled conditions than during well-mixed conditions $\left(0.23 \mathrm{~m} \mathrm{~s}^{-1}\right)$. The LTS and EIS were higher during well-mixed conditions, suggesting greater stability as compared to the decoupled conditions. The averaged BWR was 2.44 for well-mixed cases and was 1.09 for decoupled cases over SEP. This difference in BWR values is primarily due to different STBL depth and mixed-layer depth in the formulation, rather than differences in LHF and $\Delta F_{R}$. Greater-thanunity BWR for decoupled cases suggests that parameters
TABLE 5. General characteristics of well-mixed and decoupled STBLs in the SGP region. The critical $|t|$ value for $95 \%$ confidence interval is 2.07 .

\begin{tabular}{|c|c|c|c|c|c|}
\hline & \multicolumn{2}{|c|}{ Well mixed } & \multicolumn{2}{|c|}{ Decoupled } & $|t|$ \\
\hline No. of sondes & \multicolumn{2}{|c|}{35} & \multicolumn{2}{|c|}{21} & \\
\hline \multirow[b]{2}{*}{ Daytime sondes } & \multicolumn{2}{|c|}{$20(57 \%)$} & \multicolumn{2}{|c|}{$9(43 \%)$} & \\
\hline & Mean & Std dev & Mean & Std dev & \\
\hline$\theta_{v 1}-\theta_{v 0}(\mathrm{~K})$ & 0 & 0.14 & 2.35 & 2.25 & 4.78 \\
\hline$\theta_{v 2}-\theta_{v 1}(\mathrm{~K})$ & 0.05 & 0.04 & 3.06 & 3.08 & 4.47 \\
\hline$\theta_{v 3}-\theta_{v 2}(\mathrm{~K})$ & 0.03 & 0.04 & 0.60 & 0.8 & 3.26 \\
\hline Cloud base (m) & 425 & 158 & 1242 & 544 & 6.71 \\
\hline Cloud top (m) & 766 & 236 & 1497 & 503 & 6.25 \\
\hline Cloud thickness (m) & 341 & 205 & 373 & 241 & 0.50 \\
\hline $\mathrm{LCL}_{\mathrm{sfc}}(\mathrm{m})$ & 415 & 151 & 521 & 293 & 1.53 \\
\hline $\operatorname{LWP}\left(\mathrm{g} \mathrm{m}^{-2}\right)$ & 117 & 78 & 96 & 68 & 1.05 \\
\hline IWV (cm) & 1.60 & 0.77 & 1.87 & 1.23 & 0.90 \\
\hline $\mathrm{SHF}\left(\mathrm{W} \mathrm{m}^{-2}\right)$ & 39.33 & 47.67 & 20.15 & 42.27 & 1.56 \\
\hline $\mathrm{LHF}\left(\mathrm{W} \mathrm{m}^{-2}\right)$ & 36.05 & 32.30 & 37.91 & 51.96 & 0.14 \\
\hline Inversion $\Delta \theta(\mathrm{K})$ & 7.67 & 4.87 & 5.17 & 2.85 & 2.42 \\
\hline Inversion $\Delta q\left(\mathrm{~g} \mathrm{~kg}^{-1}\right)$ & -0.06 & 1.60 & -0.43 & 0.87 & 1.11 \\
\hline Inversion $\Delta Z(\mathrm{~m})$ & 200 & 154 & 110 & 57 & 3.11 \\
\hline Inversion $\Delta U\left(\mathrm{~m} \mathrm{~s}^{-1}\right)$ & 0.43 & 2.09 & 1.02 & 1.87 & 1.09 \\
\hline$\Delta \mathrm{SWF}\left(\mathrm{W} \mathrm{m}^{-2}\right)$ & 19.81 & 25.25 & 18.74 & 25.38 & 0.15 \\
\hline$\Delta \mathrm{LWF}\left(\mathrm{W} \mathrm{m}^{-2}\right)$ & -57.51 & 22.32 & -63.77 & 33.20 & 0.76 \\
\hline$\Delta F_{R}\left(\mathrm{~W} \mathrm{~m}^{-2}\right)$ & -37.70 & 28.87 & -45.02 & 36.63 & 0.78 \\
\hline$w_{\mathrm{sfc}}^{*}\left(\mathrm{~m} \mathrm{~s}^{-1}\right)$ & 0.77 & 0.48 & 0.74 & 0.67 & 0.17 \\
\hline$w_{\mathrm{rad}}^{*}\left(\mathrm{~m} \mathrm{~s}^{-1}\right)$ & 0.83 & 0.37 & 1.03 & 0.50 & 1.59 \\
\hline$u^{*}\left(\mathrm{~m} \mathrm{~s}^{-1}\right)$ & 0.37 & 0.15 & 0.31 & 0.14 & 1.51 \\
\hline$w_{\mathrm{BR}}^{*}\left(\mathrm{~ms}^{-1}\right)$ & 0 & 0 & 0 & 0 & - \\
\hline$w^{*}\left(\mathrm{~m} \mathrm{~s}^{-1}\right)$ & 1.38 & 0.32 & 1.50 & 0.35 & 1.28 \\
\hline$w_{e}\left(\mathrm{~m} \mathrm{~s}^{-1}\right)$ & 0.65 & 0.51 & 0.88 & 0.49 & 1.67 \\
\hline LTS $(\mathrm{K})$ & 20.80 & 3.77 & 18.97 & 4.50 & 1.56 \\
\hline EIS (K) & 11.39 & 4.13 & 10.05 & 5.51 & 0.96 \\
\hline
\end{tabular}

other than surface latent heat flux and radiative cooling are also responsible in producing decoupled STBL.

The decoupled STBL is deeper over the SEP compared to the well-mixed STBL (Fig. 5). Although different in depths, the STBL have remarkably similar profiles of virtual potential temperature, mixing ratio, wind speed, and radiative heating rates. The profiles of $\theta_{e}$ and $\theta_{e s}$ suggest that the STBL is weakly unstable from the surface to the inversion base during well-mixed conditions. During decoupled conditions, the STBL is unstable from the surface to $\mathrm{LCL}_{\mathrm{sfc}}$, neutral from $\mathrm{LCL}_{\mathrm{sfc}}$ to cloud-base height, and stable above that. As expected, greater amount of CAPE is present during decoupled conditions than during well-mixed conditions. The jump in $\theta_{e}$ across the STBL inversion is slightly higher during decoupled conditions than during well-mixed conditions over SEP.

\section{b. ARM Graciosa}

We identified 13 soundings (14\%) as well mixed and $43(47 \%)$ as decoupled from the GRW dataset. The mean and standard deviation values of STBL parameters, 

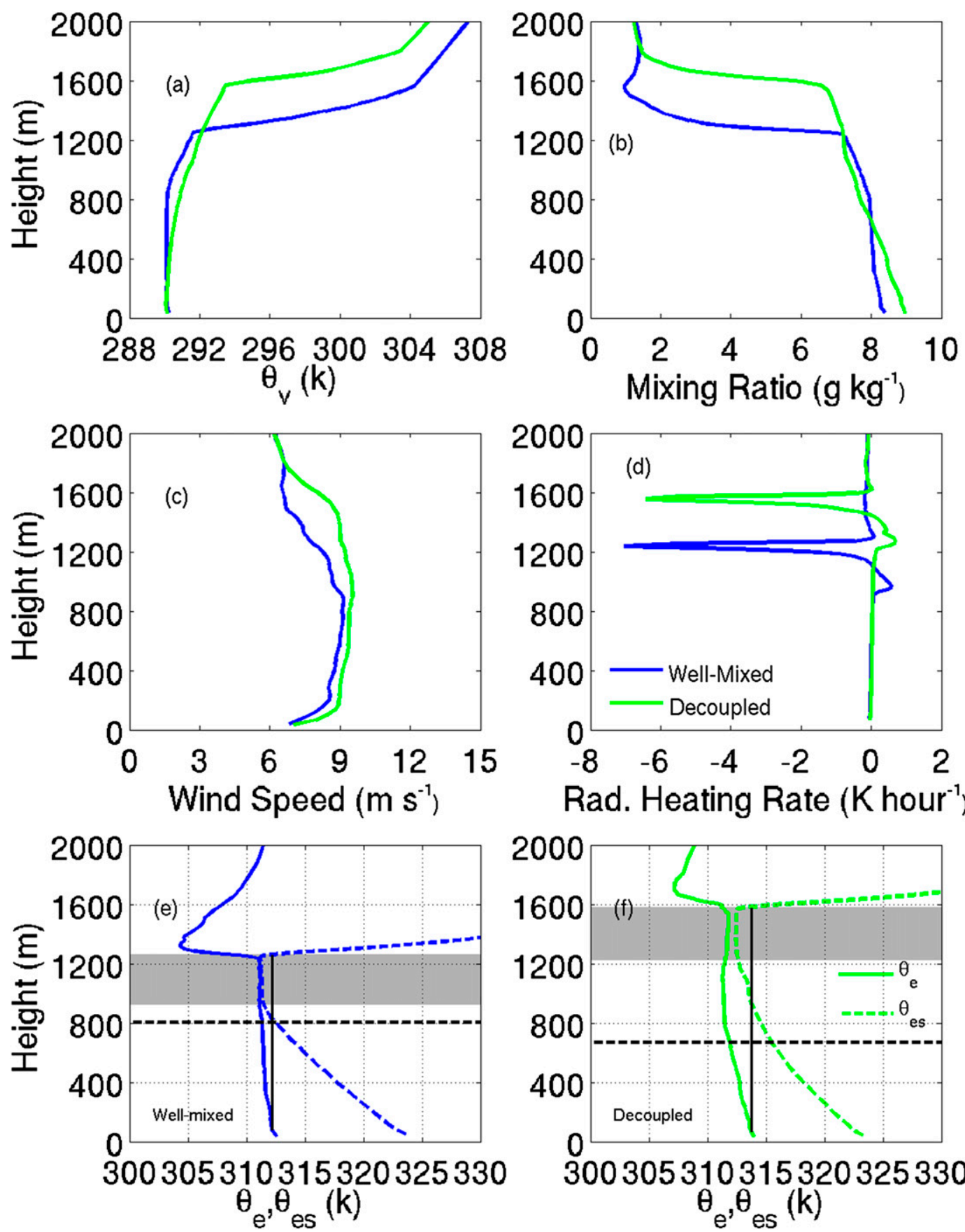

\section{Rad. Heating Rate (K hour $\left.{ }^{-1}\right)$}

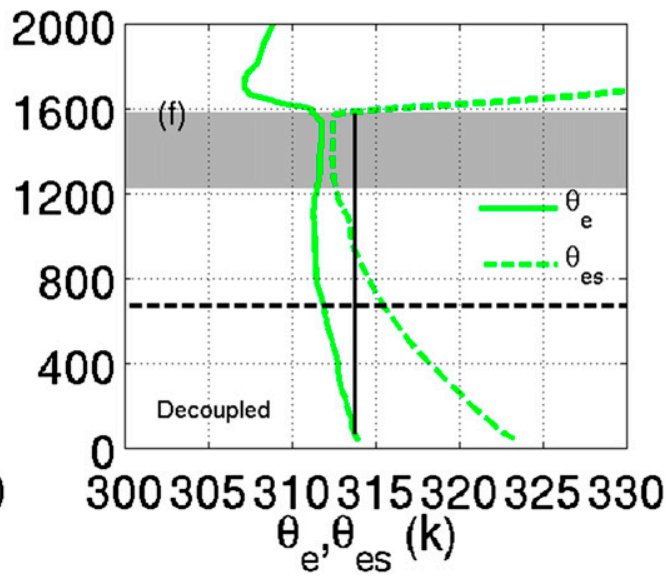

FIG. 5. Averaged profiles of (a) virtual potential temperature, (b) mixing ratio, (c) wind speed, and (d) radiative heating rate at SEP for well-mixed and decoupled modes of the STBL. (e),(f) The averaged profiles of equivalent potential temperature and saturation equivalent potential temperature for the distinction. The locations of cloud layer (gray shaded area) and $\mathrm{LCL}_{\text {sfc }}$ (black dotted line) are also shown in (e) and (f).

along with the $t$ values of the statistical significance assuming a two-tailed Gaussian distribution are reported in Table 4. The profiles of virtual potential temperature, mixing ratio, wind speed, and radiative heating rates for the thermodynamic classification are shown in Fig. 6, along with the profiles of equivalent potential temperature and saturation equivalent potential temperature.

Similar to SEP, the cloud base and cloud top over GRW were higher during decoupled conditions, as 

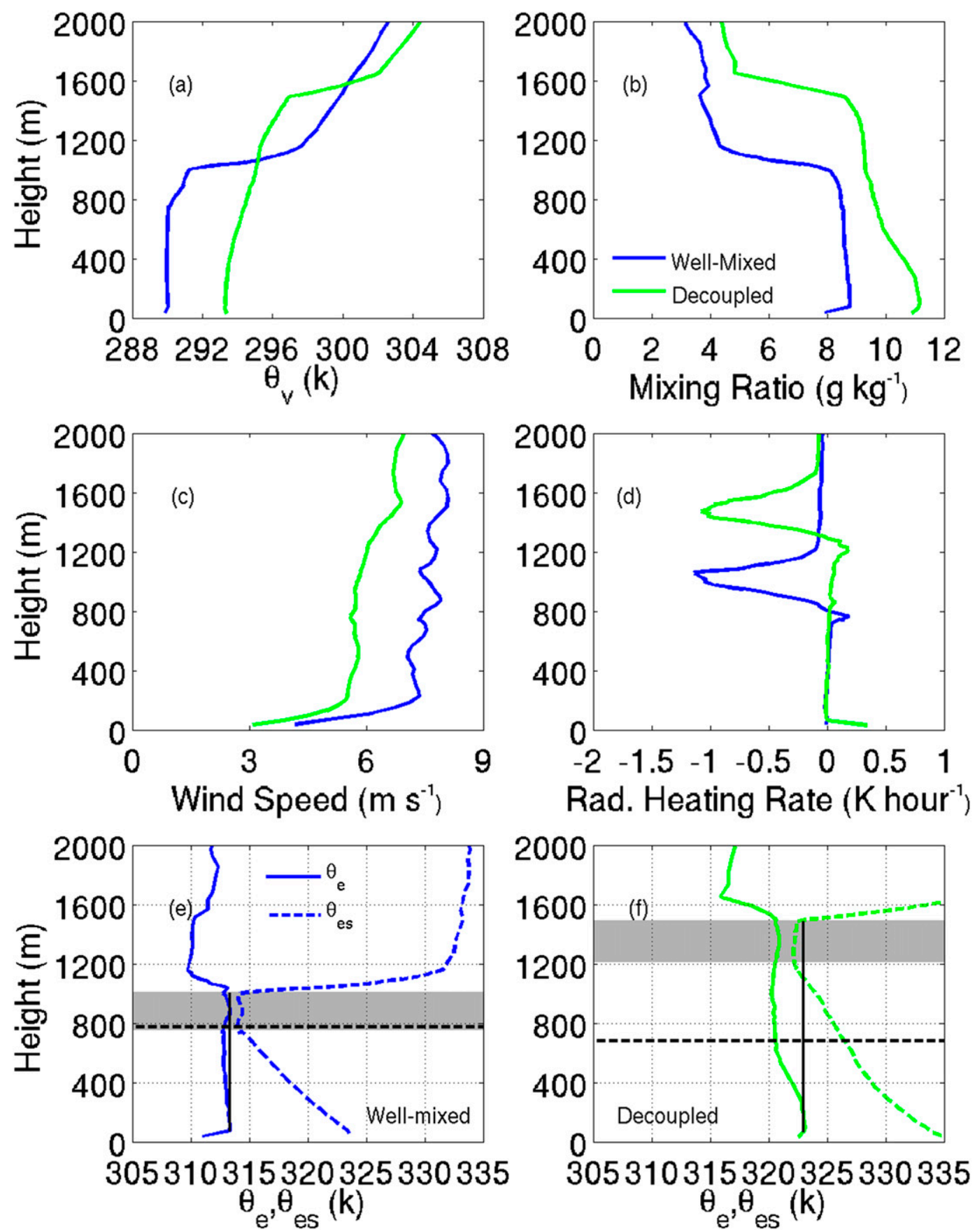

FIG. 6. Averaged profiles of (a) virtual potential temperature, (b) mixing ratio, (c) wind speed, and (d) radiative heating rate at GRW for well-mixed and decoupled modes of the STBL. (e),(f) The averaged profiles of equivalent potential temperature and saturation equivalent potential temperature for the distinction. The locations of cloud layer (gray shaded area) and $\mathrm{LCL}_{\text {sfc }}$ (black dotted line) are also shown in (e) and (f).

compared to the well-mixed conditions. The IWV was higher during decoupled conditions than during wellmixed conditions. The LHF, SHF, and LWP, along with the inversion strengths and depth, exhibited similar values for well-mixed and decoupled cases over GRW.
The shortwave, longwave, and net radiative flux divergence across the cloud layer also exhibited similar values for the well mixed versus decoupled distinction over GRW. The stability parameters (LTS and EIS) and the velocity scales (with the exception of $w_{\mathrm{BR}}^{*}$ ) did not 
exhibit any statistically significant changes for the distinction. Similar to the SEP, the averaged BWR of decoupled soundings was greater than unity, alluding that factors other than the surface latent heat flux and radiative cooling contribute toward producing decoupling at the marine locations.

The decoupled STBL over GRW were warmer and moister with lower wind speeds than the well-mixed STBL (Fig. 6). As in SEP, the radiative cooling near cloud top was similar for the well-mixed and decoupled STBL classification. The profiles of $\theta_{e}$ and $\theta_{e s}$ during the well-mixed conditions reveal the STBL to be weakly unstable from surface to the cloud top, with no CAPE. The STBL was unstable from surface to $\mathrm{LCL}_{\mathrm{sfc}}$, neutral from $\mathrm{LCL}_{\mathrm{sfc}}$ to cloud base, and weakly stable above that during decoupled conditions. The atmosphere was neutral or weakly stable above the STBL over GRW during well-mixed cases, while it was stable during the decoupled cases.

These observations broadly suggest that over GRW, the STBL is deeper, warmer, and moister, with low wind speeds during decoupled conditions compared to those during well-mixed conditions. Similar to the other marine location (SEP), the surface SHF and LHF did not exhibit any statistically significant differences between well-mixed and decoupled boundary layers.

\section{c. ARM Southern Great Plains}

From the SGP soundings, the STBL classification criteria yielded 35 (42\%) well-mixed soundings and 21 $(25 \%)$ decoupled soundings. The mean and standard deviation of the STBL parameters for the classification are reported in Table 5, along with the $t$ value of statistical significance assuming a two-tailed Gaussian distribution. The profiles of virtual potential temperature, mixing ratio, wind speed, and radiative heating rates for the thermodynamic classification are shown in Fig. 7, along with the profiles of equivalent potential temperature and saturation equivalent potential temperature for the thermodynamic distinction.

Similar to the marine locations, the decoupled STBL were, on average, deeper (higher cloud tops) than the well-mixed STBL. The increase in STBL depth from well mixed to decoupled was about $30 \%$ for SEP, $50 \%$ for GRW, and $100 \%$ over SGP. The changes in the surface fluxes, cloud thickness, LWP, and IWV were statistically insignificant for the distinction. The change in potential temperature across the STBL inversion was higher during well-mixed conditions $(7.67 \mathrm{~K})$ than during decoupled conditions $(5.17 \mathrm{~K})$. Also, the STBL inversion was almost twice as deep during well-mixed conditions $(200 \mathrm{~m})$, as compared to the decoupled conditions $(110 \mathrm{~m})$. The radiative flux divergence across the cloud layer, velocity scales and stability parameters did not exhibit a statistically significant change for the classification.

Although the surface temperatures, on average, were similar during the well-mixed and decoupled STBL cases over SGP, $\theta_{v}$ increased with height within the BL during decoupled cases, as compared to the well-mixed cases (Fig. 7). The STBL was slightly moister during decoupled cases and also had stronger winds above $800 \mathrm{~m}$, compared to the well-mixed cases. The radiative cooling near the cloud top was similar for the distinction. The profiles of $\theta_{e}$ and $\theta_{e s}$ suggest the STBL to be weakly unstable from the surface to cloud-base height and stable above that during the well-mixed conditions, while the STBL was neutral in the lowest $200 \mathrm{~m}$ of the atmosphere and stable above that during the decoupled conditions.

Broadly synthesizing the thermodynamic classification over the SGP, the decoupled STBLs were deeper with shallower $(110 \mathrm{~m})$ and weaker inversions $(\Delta \theta=$ $5.17 \mathrm{~K}$ ), as compared to the well-mixed STBLs. Also, these observations suggest no statistically significant differences in LWP, surface turbulent fluxes, radiation, or any of the velocity scales for the thermodynamic classification at SGP.

\section{Summary and discussion}

Stratocumulus clouds observed in three different regions with distinctive environments were described in the context of several variables used to parameterize them in GCMs. The primary dataset consisted of 131 soundings from the SEP, 90 soundings from the island of Graciosa (GRW) in the eastern North Atlantic, and 83 soundings from the SGP collected under single-layered stratocumulus cloud conditions. These data were used to characterize and compare the thermodynamic and radiative structures of STBLs observed at these locations. A new analysis procedure that subdivided the boundary layer into several distinct layers that were individually normalized and then recombined using a depth-preserving technique provided a fresh look at the geometry of these STBL (appendix B).

This new technique showed that the largest jump in mixing ratio across the inversion was at SEP while the smallest was at SGP. Although, the cloud boundaries observed at SEP and GRW and those at SGP and GRW exhibited statistically significant differences, the LWP did not exhibit any statistically significant differences between any of the three sites. The column-integrated water vapor (IWV) demonstrated statistically significant differences over the three sites, with highest vapor loading at GRW and lowest over SEP. Possibly because 

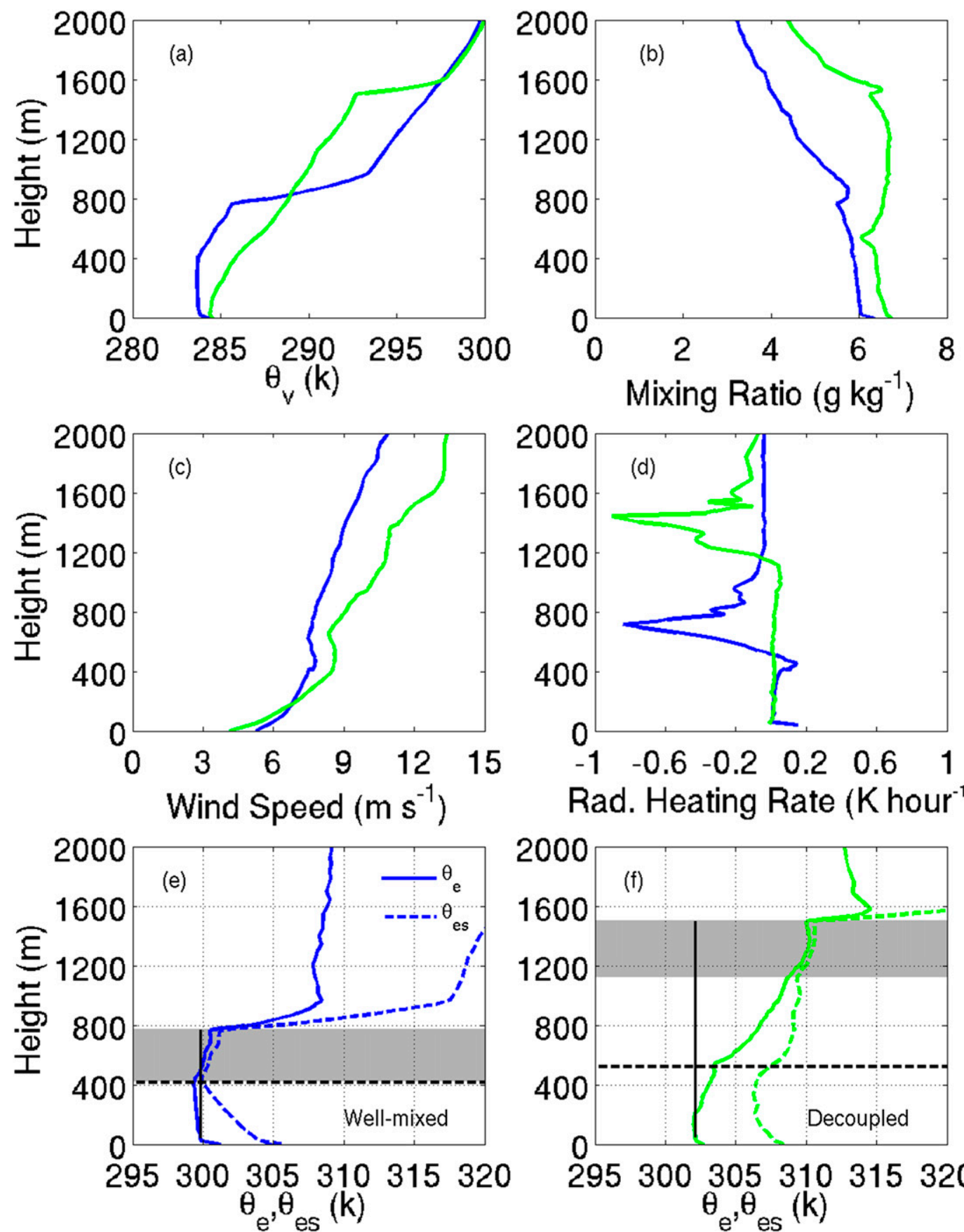

\section{Rad. Heating Rate (K hour $\left.{ }^{-1}\right)$}

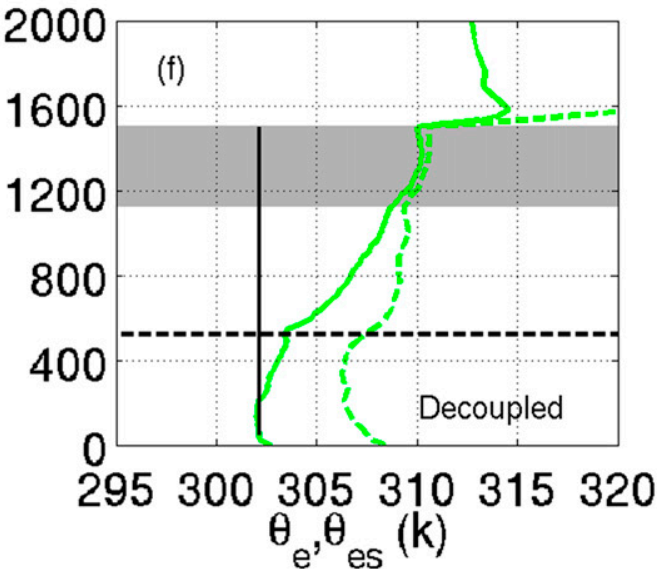

FIG. 7. Averaged profiles of (a) virtual potential temperature, (b) mixing ratio, (c) wind speed, and (d) radiative heating rate at SGP for well-mixed and decoupled modes of the STBL. (e),(f) The averaged profiles of equivalent potential temperature and saturation equivalent potential temperature for the distinction. The locations of cloud layer (gray shaded area) and $\mathrm{LCL}_{\text {sfc }}$ (black dotted line) are also shown in (e) and (f).

of a drier free troposphere and stronger inversion $(\Delta \theta$ and $\Delta q$ ), the radiative flux divergence across the cloud layer at SEP was about $40 \%$ higher than that over GRW. The greater radiative cooling across the cloud layer helps maintain a deeper STBL over SEP, as compared to that over GRW. The entrainment rates were also calculated for all of the soundings and exhibited statistically significant differences at the three locations with the highest entrainment rate observed over SGP $\left(0.69 \mathrm{~m} \mathrm{~s}^{-1}\right)$ and the lowest entrainment rate over SEP 
$\left(0.31 \mathrm{~m} \mathrm{~s}^{-1}\right)$. The thermodynamic stability parameters (LTS and EIS) also differed among the locations, with the LTS being highest over SEP and lowest over GRW and EIS being highest over SGP and lowest over GRW. It is worth noting that the spread in LTS was much lower than the spread of EIS. The BWR, which assesses the potential for decoupling to occur, was also calculated for the marine locations (SEP and GRW). The BWR was higher (3.02) over GRW than over SEP (1.66), indicating a higher potential for decoupling to occur in STBL over SEP, as compared to STBL over GRW.

The profiles of $\theta_{e}$ and $\theta_{e s}$ over SEP and GRW followed the traditional view of marine STBL (Lilly 1968), demonstrating a decrease in the $\theta_{e}$ across the STBL inversion, together with an increase in $\theta_{e s}$ values. Over the SGP, the $\theta_{e}$ and $\theta_{e s}$ values both demonstrated an increase with height above the cloud top. This did not fit with the traditional view of the thermodynamic profile of STBL and also yielded zero value for the buoyancy reversal velocity scale near cloud top (Lock et al. 2000). Indeed, one traditional model of continental stratocumuli is that they are produced by the vertical mixing of a post-cold frontal boundary layer air mass during the daytime, thereby causing it to saturate at the top. Large surface fluxes observed over the SGP seem to support this model. The average thermodynamic profiles presented here suggest that a large percentage of the stratocumuli over the SGP is not just "postfrontal mixing stratocumuli," to use the common vernacular, but are actually part of the frontal zone itself, as in Field and Wood (2007). Figure 4 suggests a warm, cloudcontaining air mass lying above a cooler, equally moist air mass, and the exceptionally large surface fluxes are likely associated with the moistening cold air mass in the lower layers. However these large fluxes seem somewhat disconnected from the stratocumuli above, as indicated by the thermodynamic profile. Together with the absence of any CAPE at SGP, it seems that a significant portion of these continental stratocumuli is probably better termed "frontal-overrunning stratocumuli."

It has been recognized for some time that the STBL seems to contain multiple modes of behavior. These modes are typically identified by their thermodynamic signature, as has been done previously by Norris (1998), Lock et al. (2000), Serpetzoglou et al. (2008), Jones et al. (2011), and many others. Inspection of individual soundings from all three regions lead us to believe in the existence of five different STBL modes: 1) well mixed; 2) stable; 3) a stable surface layer with a mixed layer above it; 4) decoupled, which consists of two mixed layers separated by a weak transition inversion; and 5) a well-mixed plus stable layer, which consists of a stable layer above a well-mixed layer. Because of a lack of sufficient samples from each of these modes, a conserved-variable analysis could not be performed to highlight the uniqueness of each of these modes. Hence, the soundings were classified as well mixed and decoupled based on the differences between the surface and cloud-base virtual potential temperature, similar to the manner used by Jones et al. (2011). The analysis revealed that the decoupled STBLs are deeper than the well-mixed STBLs at all three locations, with no statistically significant differences in the surface fluxes (SHF and LHF) at all three locations for the thermodynamic distinction. This suggests that, although deepening of the boundary layer is responsible for inducing decoupling, the role of surface fluxes in inducing warming (moistening) to produce decoupling is not so apparent. Factors like the drizzle evaporative cooling or inversion strength might be equally or more important in producing decoupling, in addition to the deepening of the boundary layer.

This study adds to a growing statistical survey of stratocumulus-topped boundary layers. While the number of soundings and the radiative transfer calculations herein are among the most comprehensive to date, they still fall well short of providing a comprehensive climatology at any of these sites. Statistically insignificant differences in LWP between the sites and also for different thermodynamic classifications (well mixed vs decoupled) suggest that some type of a control exists on the LWP through processes other than those studied in this article. Although different thermodynamic structures (Fig. B1) were noticed in the analyzed data, we were unable to carry out a conserved variable analysis (Betts and Albrecht 1987) because of a lack of enough samples. Future studies incorporating such analysis will help illuminate different processes (other than radiation and surface forcing) responsible for creating/maintaining such thermodynamic structures. Nevertheless, the presented results will be of use to the cloud-modeling community, as the thermodynamic and radiation profiles are often used as forcing for large-eddy simulation models and single-column models.

Acknowledgments. The authors wish to thank Dr. Ping Zhu for many helpful discussions about the topic, which led to significant improvement of the manuscript. The authors would also like to thank the anonymous reviewers, particularly reviewer 3 , whose comments led to a significant improvement of the manuscript. The authors also would like to thank the crew of R/V Ronald H. Brown for their support in launching the radiosondes and collecting valuable data from multiple cruises. This work was supported primarily by the U.S. Department of Energy's Atmospheric System Research, an Office of Science, Office of Biological and Environmental Research program, under Contract DE-AC02-06CH11357. MAM was supported through the Atmospheric System 
Research Grant DE-FG02-08ER64531. Some of the data were obtained from the Atmospheric Radiation Measurement Program (ARM) sponsored by the U.S. Department of Energy, Office of Science, Office of Biological and Environmental Research, Climate and Environmental Sciences Division. We thank the NOAA Climate Observation Program (COP) for their funding support.

\section{APPENDIX A}

\section{Radiative Transfer Model}

The Rapid Radiative Transfer Model (RRTM), which uses a correlated- $k$ approach to estimate the shortwave and longwave radiative fluxes and the associated heating rates, was used in this study (Mlawer et al. 1997). The RRTM input parameters were determined in a similar way as in Mather et al. (2007) and their subsequent articles. The optical properties of the water clouds are calculated per Hu and Stamnes (1993), and those of the ice clouds were calculated using $\mathrm{Fu}$ (1996) and Fu et al. (1998). The vertical resolution in the model was $10 \mathrm{~m}$ from the surface to $3 \mathrm{~km}, 50 \mathrm{~m}$ from 3 to $15 \mathrm{~km}$, and $1 \mathrm{~km}$ above $15 \mathrm{~km}$. High vertical resolution is required to resolve the boundary layer inversion, as it is often less than $100 \mathrm{~m}$ thick. Inputs for the model included the radiosonde reported temperature, pressure, and water vapor mixing ratio profiles and the cloud boundaries, together with the associated liquid water and ice water contents. Radiative effects of aerosols were neglected, as, during overcast conditions, the cloud field dominates the radiation field (Ghate et al. 2014; Tomlinson et al. 2007). The trace gases were assumed to be well mixed with height and the latest gaseous concentrations as reported by the Carbon Dioxide Information Analysis Center (CDIAC) of the Oak Ridge National Laboratory (ORNL) were used. Notably the concentration of $\mathrm{CO}_{2}$ was set to $388.5 \mathrm{ppm}$. Surface shortwave albedo was assumed to be 0.05 for GRW and SEP and 0.22 for SGP. The cloud water contents were estimated using the radar reflectivity $Z$ and $Z$-LWC relationship proposed by Matrosov et al. (2004) for liquid clouds and the Z-IWC relationship proposed by Liu and Illingworth (2000) for ice clouds. The cloud droplet effective radius for the liquid clouds was calculated by assuming a lognormal drop size distribution with a width of 0.35 and a number concentration of $74 \mathrm{~cm}^{-3}$ (Miles et al. 2000). The effective radius of ice crystals within cirrus clouds was determined using the temperature-dependent relationship proposed by Ivanova et al. (2001). Cloud radar data were not available for the SEP region during all the cruises. Hence, the LWC profile was calculated by scaling the observed hourly averaged LWP to that of an adiabatic LWC profile, thereby

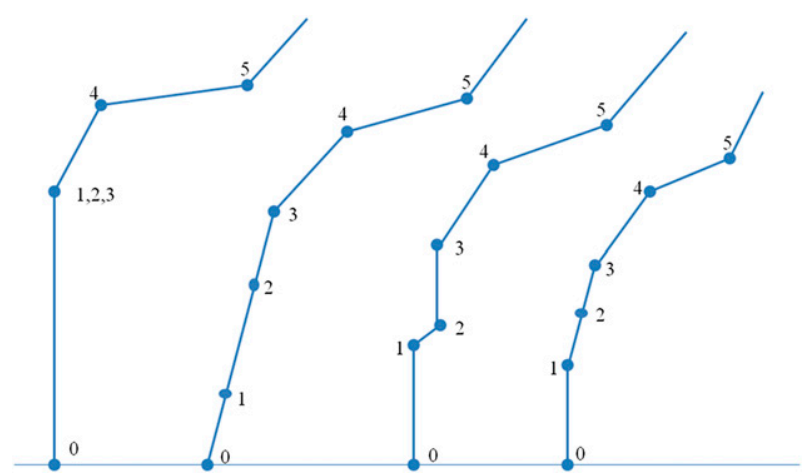

FIG. B1. Profiles of virtual potential temperature for (left)-(right) a well-mixed STBL, a stable STBL, a classic decoupled STBL with two mixed layers, and an STBL with a stable layer above the mixed layer. Point 0 represents the 100-m height for GRW and 50-m height for SGP and SEP and was used as a surrogate for surface temperature. Points 1-5 represent $\mathrm{LCL}_{\mathrm{sfc}}, \mathrm{LCL}_{\mathrm{CB}}$, cloud-base height, inversion-base height, and inversion-top height, respectively.

providing an approximation of cloud depth. We believe that this approximation is justified on the basis of past studies of the adiabatic character of stratocumulus beneath a strong inversion. Also because of the absence of cloud radar data, no observations of high-level cirrus clouds were available for the SEP region; hence, radiative effects of cirrus clouds were not accounted for in the SEP region. It should be noted that previous studies (Ghate et al. 2009; Leon et al. 2008; etc.) have shown the cirrus cloud cover to be very low in the region. Hence, we deem exclusion of cirrus clouds from the RRTM simulation not to be a major issue. To be consistent with the temporal resolution of the cloud radar, the model runs were made every $10 \mathrm{~s}$ for the SGP cases and every $5 \mathrm{~s}$ for the GRW cases. Only one model run for each sounding was made for the SEP data because of the unavailability of the cloud radar data, but we deem this estimate as a crucial comparator to the other datasets. The radiative effects of drizzle below the ceilometer-detected cloud-base height were neglected in the radiative transfer calculations.

\section{APPENDIX B}

\section{Averaging Technique}

Various methods have been proposed to generate averaged soundings from an ensemble dataset of STBL soundings (e.g., Betts and Albrecht 1987; Yin and Albrecht 2000; Serpetzoglou et al. 2008; Rémillard et al. 2012). For soundings with near-similar inversion-base heights and similar profiles, an average sounding can be produced without normalizing the individual soundings by their inversion base. This was implemented by Betts and Albrecht (1987) and Yin and Albrecht (2000). To accommodate 

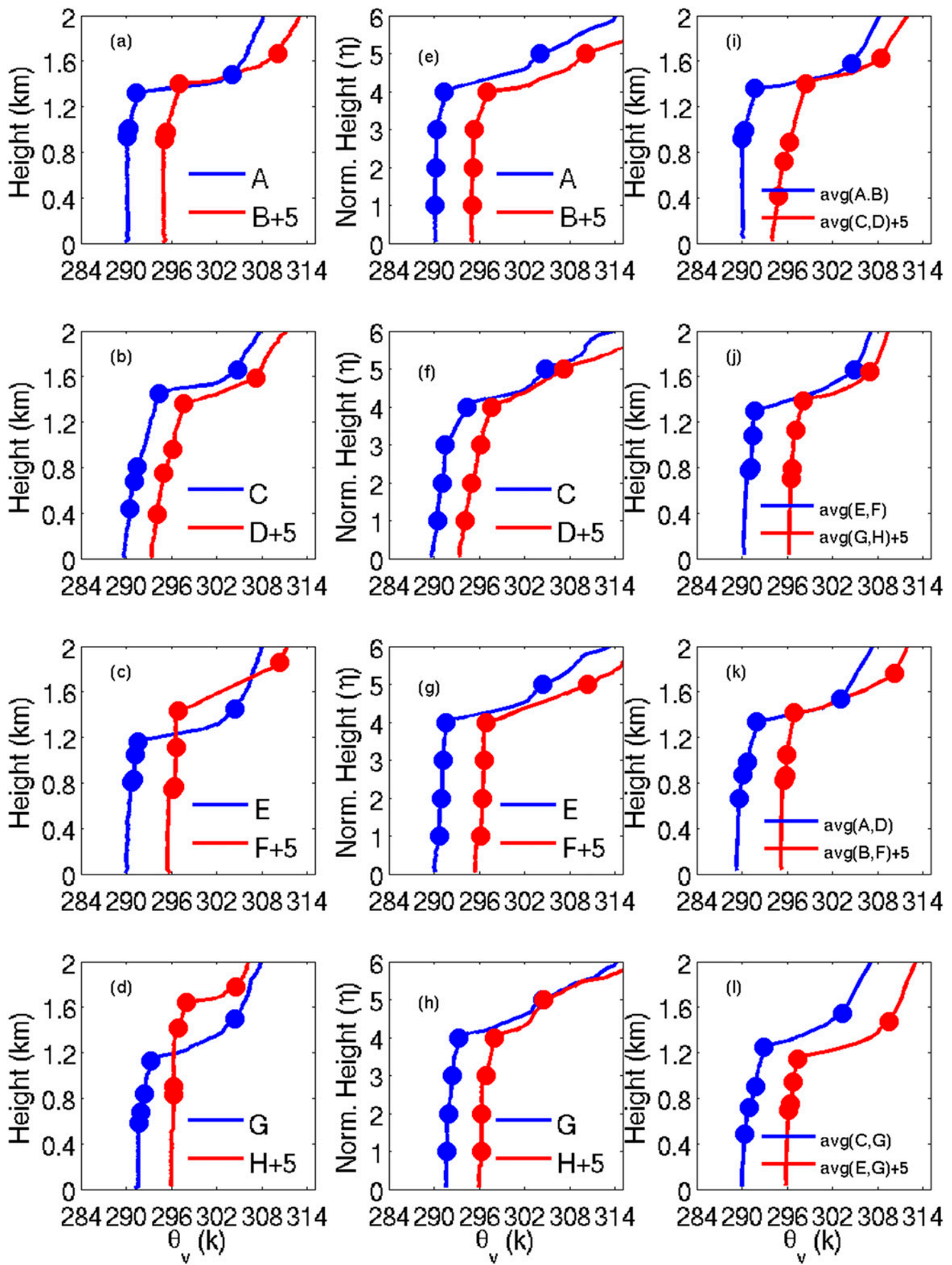

FIG. B2. Examples of profiles of (a)-(d) virtual potential temperature, (e)-(h) virtual potential temperature profiles as a function of normalized height, and (i)-(l) virtual potential temperature averaged using the proposed averaging procedure. The circles correspond to the $\mathrm{LCL}_{\mathrm{sfc}}, \mathrm{LCL}_{\mathrm{CB}}$, cloud-base height, cloud-top height, and inversion-top height from the bottom to the top in each profile. Please refer to the text for more details. 
soundings with different BL depths (inversion-base height), Serpetzoglou et al. (2008) and Rémillard et al. (2012) normalized the soundings with respect to the inversionbase height before averaging them together. Although the approach used by these studies is novel, averaging the soundings after normalizing it with respect to the inversion-base height does not take into account the thickness of different sublayers within the BL (cloud layer, mixed layer, etc.), leading to an averaged profile having different thermodynamic and radiative properties than the original soundings. To circumvent this difficulty, we developed a new averaging technique that divides the boundary layer into five different layers (Fig. B1), each having unique thermodynamic and radiative properties. The proposed averaging technique makes an attempt to preserve the structure and properties of the different layers within individual soundings.

Shown in Fig. B1 (from left to right) are the profiles of virtual potential temperature for a well-mixed STBL, a stable STBL, a classic decoupled STBL, and a STBL that has a stable layer above a well-mixed layer. Visual inspection of individual soundings by the authors yielded these profiles. Each of these profiles has a different boundary layer depth, and also the thicknesses of different layers within the STBL (the cloud layer, well-mixed layer, etc.) are different.

Listed below are the steps of the proposed averaging procedure:

1) Identify the cloud-base height, cloud-top height (inversion-base height), and the inversion-top height. Calculate the lifting condensation level (LCL) at each height below the cloud base.

2) Identify the LCL corresponding to the surface-based measurements and term that height as $\mathrm{LCL}_{\mathrm{sfc}}$.

3) Identify a height above and closest to $\mathrm{LCL}_{\text {sfc }}$ whose LCL value matches (within $20 \mathrm{~m}$ ) the cloud-base height, and term it $\mathrm{LCL}_{\mathrm{CB}}$. This ensures the $\mathrm{LCL}_{\mathrm{CB}}$ to be above $\mathrm{LCL}_{\mathrm{sfc}}$.

4) Identify five layers for each sounding: a layer from the surface to $\mathrm{LCL}_{\mathrm{sfc}}$, a layer between $\mathrm{LCL}_{\mathrm{sfc}}$ and $\mathrm{LCL}_{\mathrm{CB}}$, a layer from $\mathrm{LCL}_{\mathrm{CB}}$ to cloud base, a cloud layer between cloud-base height and inversion-base height, and an inversion layer between inversion-base height and inversion-top height. Calculate the average thickness of these layers for the selected soundings.

5) Normalize each layer with respect to its thickness so as to have the normalized height of

- $0-1$ from the surface to $\mathrm{LCL}_{\mathrm{sfc}}$;

- 1-2 from $\mathrm{LCL}_{\mathrm{sfc}}$ to $\mathrm{LCL}_{\mathrm{CB}}$;

- 2-3 from $\mathrm{LCL}_{\mathrm{CB}}$ to cloud-base height;

- 3-4 from cloud-base height to cloud top;

- 4-5 from cloud-top height to inversion-top height; and

- 5 to any desirable value above that.
6) Average the selected soundings to produce a profile as a function of normalized height.

7) Multiply the respective normalized heights of each layer with their average thicknesses calculated in step 4 to produce a profile in regular height (in meters).

In this study, the LCL calculated at the 50-m height was used as a surrogate for LCL calculated from surfacebased measurements (termed $\mathrm{LCL}_{\mathrm{sfc}}$ ) for the soundings from SEP and SGP, while because of island effects, the LCL at the 100-m height was used as a surrogate for the surface LCL for GRW radiosondes. These levels were chosen by visual inspection of the data and deemed to be above the surface layer.

A few examples of the averaging procedure are displayed in Fig. B2. Shown in Figs. B2a-d are eight individual soundings $(\mathrm{A}-\mathrm{H})$, with the circles representing the five levels that are used for the purpose of normalization. The profiles of the same soundings $(\mathrm{A}-\mathrm{H})$ as a function of normalized height are shown in Figs. B2e-h. Shown in Figs. B2i-1 are the averaged profiles of the different soundings $(\mathrm{A}-\mathrm{H})$ produced using the averaging technique described above. Profiles A and B are well mixed and coupled to the surface, and so is the averaged profile of the two (Fig. B2i). Analogous statements are true for the stable thermodynamic profiles (C and D), the classic decoupled thermodynamic profiles (E and $\mathrm{F}$ ), and the well-mixed plus stable profiles $(\mathrm{G}$ and $\mathrm{H})$. Also, in all these averaged profiles, the structure of the inversion layer is maintained, which is crucial for radiative transfer calculations. As the technique preserves the identity of different layers, it can be seen that averaging a well-mixed layer (A) together with a stable layer (D) produces a structure similar to a well-mixed plus stable profile (Fig. B2k).

\section{REFERENCES}

Abdul-Wahab, S. A., 2003: Analysis of thermal inversions in the Khareef Salalah region in the Sultanate of Oman. J. Geophys. Res., 108, 4274, doi:10.1029/2002JD003083.

Albrecht, B. A., D. A. Randall, and S. Nicholls, 1988: Observations of marine stratocumulus clouds during FIRE. Bull. Amer. Meteor. Soc., 69, 618-626, doi:10.1175/1520-0477(1988)069<0618: OOMSCD $>2.0 . \mathrm{CO} ; 2$.

, C. S. Bretherton, D. W. Johnson, W. H. Schubert, and A. Shelby Frisch, 1995: The Atlantic Stratocumulus Transition Experiment-ASTEX. Bull. Amer. Meteor. Soc., 76, 889-904, doi:10.1175/1520-0477(1995)076<0889:TASTE >2.0.CO;2.

Bechtold, P., S. K. Krueger, W. S. Lewellen, E. van Meijgaard, C. H. Moeng, D. A. Randall, A. van Ulden, and S. Wang, 1996: Modeling a stratocumulus-topped PBL: Intercomparison among different one-dimensional codes and with large eddy simulation. Bull. Amer. Meteor. Soc., 77, 2033-2042. 
Betts, A. K., and B. A. Albrecht, 1987: Conserved variable analysis of the convective boundary layer thermodynamic structure over the tropical oceans. J. Atmos. Sci., 44, 83-99, doi:10.1175/ 1520-0469(1987)044<0083:CVAOTC $>2.0$. CO;2

Bolton, D., 1980: The computation of equivalent potential temperature. Mon. Wea. Rev., 108, 1046-1053, doi:10.1175/ 1520-0493(1980)108<1046:TCOEPT > 2.0.CO;2.

Bony, S., and J.-L. Dufresne, 2005: Marine boundary layer clouds at the heart of tropical cloud feedback uncertainties in climate models. Geophys. Res. Lett., 32, L20806, doi:10.1029/ 2005GL023851.

Bretherton, C. S., and M. C. Wyant, 1997: Moisture transport, lower-tropospheric stability, and decoupling of cloud-topped boundary layers. J. Atmos. Sci., 54, 148-167, doi:10.1175/ 1520-0469(1997)054<0148:MTLTSA > 2.0.CO;2.

—, and S. Park, 2009: A new moist turbulence parameterization in the Community Atmosphere Model. J. Climate, 22, 34223448, doi:10.1175/2008JCLI2556.1.

Brotzge, J. A., and K. C. Crawford, 2003: Examination of the surface energy budget: A comparison of eddy correlation and Bowen ratio measurement systems. J. Hydrometeor., 4, 160178, doi:10.1175/1525-7541(2003)4<160:EOTSEB > 2.0.CO;2.

Brunke, M. A., Z. Wang, X. Zeng, M. Bosilovich, and C.-L. Shie, 2011: An assessment of the uncertainties in ocean surface turbulent fluxes in 11 reanalysis, satellite-derived, and combined global datasets. J. Climate, 24, 5469-5493, doi:10.1175/ 2011JCLI4223.1.

Caldwell, P., C. S. Bretherton, and R. Wood, 2005: Mixed-layer budget analysis of the diurnal cycle of entrainment in southeast Pacific stratocumulus. J. Atmos. Sci., 62, 3775-3791, doi:10.1175/JAS3561.1.

Comstock, K. K., C. S. Bretherton, and S. E. Yuter, 2005: Mesoscale variability and drizzle in southeast Pacific stratocumulus. J. Atmos. Sci., 62, 3792-3807, doi:10.1175/JAS3567.1.

- S. E. Yuter, R. Wood, and C. S. Bretherton, 2007: The threedimensional structure and kinematics of drizzling stratocumulus. Mon. Wea. Rev., 135, 3767-3784, doi:10.1175/2007MWR1944.1.

de Szoeke, S. P., S. Yuter, D. Mechem, C. W. Fairall, C. D. Burleyson, and P. Zuidema, 2012: Observations of stratocumulus clouds and their effect on the eastern Pacific surface heat budget along $20^{\circ}$ S. J. Climate, 25, 8542-8567, doi:10.1175/ JCLI-D-11-00618.1.

Fairall, C. W., E. F. Bradley, J. E. Hare, A. A. Grachev, and J. B. Edson, 2003: Bulk parameterization of air-sea fluxes: Updates and verification for the COARE algorithm. J. Climate, 16, 571-591, doi:10.1175/1520-0442(2003)016<0571: BPOASF $>2.0 . \mathrm{CO} ; 2$.

Field, P. R., and R. Wood, 2007: Precipitation and cloud structure in midlatitude cyclones. J. Climate, 20, 233-254, doi:10.1175/ JCLI3998.1.

Fu, Q., 1996: An accurate parameterization of the solar radiative properties of cirrus clouds for climate models. J. Climate, 9, 2058-2082, doi:10.1175/1520-0442(1996)009<2058: AAPOTS $>2.0 . \mathrm{CO} ; 2$

$\longrightarrow$, P. Yang, and W. B. Sun, 1998: An accurate parameterization of the infrared radiative properties of cirrus clouds for climate models. J. Climate, 11, 2223-2237, doi:10.1175/ 1520-0442(1998)011<2223:AAPOTI>2.0.CO;2.

Ghate, V. P., B. A. Albrecht, C. W. Fairall, and R. A. Weller, 2009: Climatology of surface meteorology, surface fluxes, cloud fraction, and radiative forcing over the southeast Pacific from buoy observations. J. Climate, 22, 5527-5540, doi:10.1175/ 2009JCLI2961.1.
- — - , and P. Kollias, 2010: Vertical velocity structure of nonprecipitating continental boundary layer stratocumulus clouds, J. Geophys. Res., 115, D13204, doi:10.1029/ 2009JD013091.

- — - M. A. Miller, A. Brewer, and C. W. Fairall, 2014: Turbulence and radiation in stratocumulus-topped marine boundary layers: A case study from VOCALS-REx. J. Appl. Meteor. Climatol., 53, 117-135, doi:10.1175/JAMC-D-12-0225.1.

Golaz, J.-C., V. E. Larson, and W. R. Cotton, 2002: A PDF-based model for boundary layer clouds. Part I: Method and model description. J. Atmos. Sci., 59, 3540-3551, doi:10.1175/ 1520-0469(2002)059<3540:APBMFB > 2.0.CO;2.

$\mathrm{Hu}$, Y. X., and K. Stamnes, 1993: An accurate parameterization of the radiative properties of water clouds suitable for use in climate models. J. Climate, 6, 728-742, doi:10.1175/ 1520-0442(1993)006<0728:AAPOTR >2.0.CO;2.

Ivanova, D., D. L. Mitchell, W. P. Arnott, and M. Poellot, 2001: A GCM parameterization for bimodal size spectra and ice mass removal rates in mid-latitude cirrus clouds. Atmos. Res., 5960, 89-113, doi:10.1016/S0169-8095(01)00111-9.

Jones, C. R., C. S. Bretherton, and D. Leon, 2011: Coupled vs. decoupled boundary layers in VOCALS-REx. Atmos. Chem. Phys., 11, 7143-7153, doi:10.5194/acp-11-7143-2011.

Klein, S. A., and D. L. Hartmann, 1993: The seasonal cycle of low stratiform clouds. J. Climate, 6, 1587-1606, doi:10.1175 1520-0442(1993)006<1587:TSCOLS $>2.0$. CO;2.

Kollias, P., G. Tselioudis, and B. A. Albrecht, 2007: Cloud climatology at the Southern Great Plains and the layer structure, drizzle, and atmospheric modes of continental stratus. J. Geophys. Res., 112, D09116, doi:10.1029/2006JD007307.

Lappen, C.-L., and D. A. Randall, 2001: Toward a unified parameterization of the boundary layer and moist convection. Part I: A new type of mass-flux model. J. Atmos. Sci., 58, 2021-2036, doi:10.1175/1520-0469(2001)058<2021: TAUPOT $>2.0 . \mathrm{CO} ; 2$.

Larson, V. E., D. P. Schanen, M. Wang, M. Ovchinnikov, and S. Ghan, 2012: PDF parameterization of boundary layer clouds in models with horizontal grid spacings from 2 to $16 \mathrm{~km}$. Mon. Wea. Rev., 140, 285-306, doi:10.1175/MWR-D-10-05059.1.

Leon, D. C., Z. Wang, and D. Liu, 2008: Climatology of drizzle in marine boundary layer clouds based on 1 year of data from CloudSat and Cloud-Aerosol Lidar and Infrared Pathfinder Satellite Observations (CALIPSO). J. Geophys. Res., 113, D00A14, doi:10.1029/2008JD009835.

Lilly, D., 1968: Models of cloud-topped mixed layers under a strong inversion. Quart. J. Roy. Meteor. Soc., 94, 292-309, doi:10.1002/ qj. 49709440106.

Liu, C.-L., and A. J. Illingworth, 2000: Toward more accurate retrievals of ice water content from radar measurements of clouds. J. Appl. Meteor., 39, 1130-1146, doi:10.1175/ 1520-0450(2000)039<1130:TMAROI >2.0.CO;2.

Lock, A. P., 2009: Factors influencing cloud area at the capping inversion for shallow cumulus clouds. Quart. J. Roy. Meteor. Soc., 135, 941-952, doi:10.1002/qj.424.

_ , and M. K. Macvean, 1999: The parameterization of entrainment driven by surface heating and cloud-top cooling. Quart. J. Roy. Meteor. Soc., 125, 271-299, doi:10.1002/qj.49712555315.

—, A. R. Brown, M. R. Bush, G. M. Martin, and R. N. B. Smith, 2000: A new boundary layer mixing scheme. Part I: Scheme description and single-column model tests. Mon. Wea. Rev., 128, 3187-3199, doi:10.1175/1520-0493(2000)128<3187: ANBLMS $>2.0$. CO;2; Corrigendum, 129, 905-905, doi:10.1175/ 1520-0493(2001)129<0905:C >2.0.CO;2. 
Mather, J. H., and J. W. Voyles, 2013: The ARM Climate Research Facility: A review of structure and capabilities. Bull. Amer. Meteor. Soc., 94, 377-392, doi:10.1175/BAMS-D-11-00218.1.

_ S. A. McFarlane, M. A. Miller, and K. L. Johnson, 2007: Cloud properties and associated radiative heating rates in the tropical western Pacific. J. Geophys. Res., 112, D05201, doi:10.1029/2006JD007555.

Matrosov, S. Y., T. Uttal, and D. A. Hazen, 2004: Evaluation of radar reflectivity-based estimates of water content in stratiform marine clouds. J. Appl. Meteor., 43, 405-419, doi:10.1175/ 1520-0450(2004)043<0405:EORREO > 2.0.CO;2.

Mechem, D. B., Y. L. Kogan, and D. M. Schultz, 2010: Large-eddy observation of post-cold-frontal continental stratocumulus. J. Atmos. Sci., 67, 3368-3383, doi:10.1175/2010JAS3389.1.

Medeiros, B., D. L. Williamson, C. Hannay, and J. G. Olson, 2012: Southeast Pacific stratocumulus in the Community Atmosphere Model. J. Climate, 25, 6175-6192, doi:10.1175/ JCLI-D-11-00503.1.

Miles, N. L., J. Verlinde, and E. E. Clothiaux, 2000: Cloud droplet size distributions in low-level stratiform clouds. J. Atmos. Sci., 57, 295-311, doi:10.1175/1520-0469(2000)057<0295: CDSDIL $>2.0 . \mathrm{CO} ; 2$.

Miller, M. A., and B. A. Albrecht, 1995: Surface-based observations of mesoscale cumulus-stratocumulus interaction during ASTEX. J. Atmos. Sci., 52, 2809-2826, doi:10.1175/ 1520-0469(1995)052<2809:SBOOMC >2.0.CO;2.

Miller, R. L., 1997: Tropical thermostats and low cloud cover. J. Climate, 10, 409-440, doi:10.1175/1520-0442(1997)010<0409: TTALCC $>2.0 . \mathrm{CO} ; 2$.

Mlawer, E. J., S. J. Taubman, P. D. Brown, M. J. Iacono, and S. A. Clough, 1997: Radiative transfer for inhomogeneous atmospheres: RRTM, a validated correlated-k model for the longwave. J. Geophys. Res., 102, 16 663-16 682, doi:10.1029/ 97JD00237.

Moeng, C.-H., and Coauthors, 1996: Simulation of a stratocumulustopped planetary boundary layer: Intercomparison among different numerical codes. Bull. Amer. Meteor. Soc., 77, 261-278, doi:10.1175/1520-0477(1996)077<0261:SOASTP > 2.0.CO;2.

Norris, J. R., 1998: Low cloud type over the ocean from surface observations. Part I: Relationship to surface meteorology and the vertical distribution of temperature and moisture. J. Climate, 11, 369-382, doi:10.1175/1520-0442(1998)011<0369: LCTOTO $>2.0 . \mathrm{CO} ; 2$.

Rasch, P. J., and J. E. Kristjánsson, 1998: A comparison of CCM3 model climate using diagnosed and predicted condensate parameterizations. J. Climate, 11, 1587-1614, doi:10.1175/ 1520-0442(1998)011<1587:ACOTCM>2.0.CO;2.
Rémillard, J., P. Kollias, E. Luke, and R. Wood, 2012: Marine boundary layer cloud observations in the Azores. J. Climate, 25, 7381-7398, doi:10.1175/JCLI-D-11-00610.1.

Serpetzoglou, E., B. A. Albrecht, P. Kollias, and C. W. Fairall, 2008: Boundary layer, cloud, and drizzle variability in the southeast Pacific stratocumulus regime. J. Climate, 21, 6191-6214, doi:10.1175/2008JCLI2186.1.

Stevens, B., W. R. Cotton, G. Feingold, and C.-H. Moeng, 1998: Large-eddy simulations of strongly precipitating, shallow, stratocumulus-topped boundary layers. J. Atmos. Sci., 55, 36163638, doi:10.1175/1520-0469(1998)055<3616:LESOSP > 2.0.CO;2.

— Stratocumulus-DYCOMS-II. Bull. Amer. Meteor. Soc., 84, 579-593, doi:10.1175/BAMS-84-5-579.

— via observations of nocturnal marine stratocumulus. Mon. Wea. Rev., 133, 1443-1462, doi:10.1175/MWR2930.1.

Stull, R. B., 1988: An Introduction to Boundary Layer Meteorology. Springer, $670 \mathrm{pp}$.

Tomlinson, J. M., R. Li, and D. R. Collins, 2007: Physical and chemical properties of the aerosol within the southeastern Pacific marine boundary layer. J. Geophys. Res., 112, D12211, doi:10.1029/2006JD007771.

Wang, Q., and B. A. Albrecht, 1994: Observations of cloud-top entrainment in marine stratocumulus clouds. J. Atmos. Sci., 51, 1530 1547, doi:10.1175/1520-0469(1994)051<1530:OOCTEI > 2.0.CO;2.

Wood, R., 2012: Stratocumulus clouds. Mon. Wea. Rev., 140, 2373 2423, doi:10.1175/MWR-D-11-00121.1.

— , and C. S. Bretherton, 2006: On the relationship between stratiform low cloud cover and lower-tropospheric stability. J. Climate, 19, 6425-6432, doi:10.1175/JCLI3988.1.

— , and Coauthors, 2011: The VAMOS Ocean-Cloud-AtmosphereLand Study Regional Experiment (VOCALS-REx): Goals, platforms, and field operations. Atmos. Chem. Phys., 11, 627-654, doi:10.5194/acp-11-627-2011.

Wyant, M. C., and Coauthors, 2007: A single-column model intercomparison of a heavily drizzling stratocumulus-topped boundary layer. J. Geophys. Res., 112, D24204, doi:10.1029/ 2007JD008536.

Yin, B., and B. A. Albrecht, 2000: Spatial variability of atmospheric boundary layer structure over the eastern equatorial Pacific. J. Climate, 13, 1574-1592, doi:10.1175/1520-0442(2000)013<1574: SVOABL $>2.0 . \mathrm{CO} ; 2$.

Zhu, P., and Coauthors, 2005: Intercomparison and interpretation of single-column model simulations of a nocturnal stratocumulustopped marine boundary layer. Mon. Wea. Rev., 133, 2741-2758, doi:10.1175/MWR2997.1. 